Para enlazar con este artículo / To link to this article:

http://dx.doi.org/10.6035/MonTI.2020.ne6.8

Para citar este artículo / To cite this article:

López Ruiz, María del Carmen. (2020) "La recepción y traducción de unidades fraseológicas en el discurso político. Análisis de un corpus ad hoc (EN, FR > ES)." En: Mogorrón Huerta, Pedro (ed.) 2020. Análisis multidisciplinar del fenómeno de la variación fraseológica en traducción e interpretación / Multidisciplinary Analysis of the Phenomenon of Phraseological Variation in Translation and Interpreting. MonTI Special Issue 6, pp. 248-286.

\title{
LA RECEPCIÓN Y TRADUCCIÓN DE UNIDADES FRASEOLÓGICAS EN EL DISCURSO POLÍTICO. ANÁLISIS DE UN CORPUS AD HOC (EN, FR > ES) ${ }^{1}$
}

\author{
THE RECEPTION AND TRANSLATION OF PHRASEOLOGICAL \\ UNITS IN POLITICAL SPEECHES. ANALYSIS OF AN AD HOC \\ CORPUS (EN, FR > ES)
}

\author{
MARÍA DEL CARMEN LÓPEZ RUIZ \\ maricarmen.lopezruiz@uco.es \\ Universidad de Córdoba (España)
}

\section{Resumen}

El objetivo de este trabajo es investigar las UFS más habituales en los discursos políticos partiendo de las premisas que se han abordado hasta el momento en este lenguaje de especialidad en relación con la fraseología (Coseriu, 1987; Van Dijk, 1996; Navarro, 2002; Fuentes et al., 2002). Adoptando una visión traductológica, mostraremos las UFS halladas en un corpus de trabajo compuesto por discursos políticos en inglés y en francés con su correspondiente traducción hacia el español. La intención es clasificar las UFS para obtener resultados cuantitativos en lo referente a la fraseología del discurso político, tanto en el corpus de discursos en inglés como en el de francés, para así poder obtener una visión más completa de los diferentes tipos de UFS que se hallan en el discurso político y sus porcentajes correspondientes. El resultado de nuestra

1. La presente contribución forma parte de la tesis doctoral que lleva a cabo actualmente la autora en el marco del contrato para la Formación del Profesorado Universitario (FPU) en la Universidad de Córdoba. Dicha investigación está respaldada económicamente por el Ministerio de Universidades de España. 
investigación nos permitirá elaborar un glosario trilingüe cuya finalidad es servir de referencia durante el proceso de documentación de otros especialistas en el tema.

Palabras clave: Traducción; Fraseología; Discurso Político; Traducción Especializada; Unidades Fraseológicas.

\begin{abstract}
This paper examines the most frequent PUs in political speeches, considering previous works in phraseological studies with regards to this specialized language by authors such as Coseriu, 1987; Van Dijk, 1996; Navarro, 2002 or Fuentes el al., 2002. We intend to display from a traductological point of view all the different PUs found in our corpus of work, composed by English and French political speeches, as well as their corresponding translations into Spanish. Our goal is to classify such PUs in order to obtain quantitative results regarding phraseology in our corpus, and thus attain a broader view of the types of PUs that are commonly used in political speeches and their corresponding percentage frequency. Results will let us bring out a trilingual glossary in our attempt to help other specialists throughout their documentation process when translating.
\end{abstract}

Keywords: Translation; Phraseology; Political Discourse; Specialized Translation; Phraseological Units.

\title{
1. Fraseología y discurso político. Estado de la cuestión
}

El estudio de la fraseología se ha abordado desde diferentes prismas teóricos. Tanto es así que no sorprende encontrar contribuciones enfocadas desde la perspectiva lingüística (Coseriu 1987; Corpas Pastor 1997; Zuluaga 1997; Martínez Marín 1996; Navarro 2002; García Page Sánchez 2008), la didáctica (García Yelo 2005; García Romero \& Sevilla Muñoz 2005; Higueras García 2009; Serrano Lucas 2010; Brazo Millán 2018) o la contrastiva (Lozano 1992; Gutiérrez Díez 1995; Sevilla Muñoz 1997; Corpas Pastor 2003; Radulescu 2006; Timofeeva 2012; Mogorrón Huerta 2014). Sin embargo, lo que interesa para los objetivos de esta contribución es conocer cuál es el estado de la cuestión en lo que concierne a las UFS y el discurso político.

Como sugieren los estudios dedicados a este último, cada vez hay más interés en abordar este terreno por parte tanto de investigadores/as como 
de grupos de investigación. Lo que destaca la mayor parte de las publicaciones que abordan la fraseología del discurso político es la capacidad que tienen estas unidades para aportar énfasis a la eficacia comunicativa del discurso. Así lo prueban autores como Van Dijk 1996; Tannen 1999; Fernández Lagunilla 1999a; Navarro 2002; Fabbri et al. 2002; Nuñez Cabezas et al. 2002; Fuentes et al. 2002; Arce Castillo 2006; Arellano et al. 2013 o Messina Fajardo 2016.

Si consideramos las conclusiones a las que llegan todos estos autores, podríamos decir que las diferentes UFS se insertan a lo largo del discurso político para cumplir diferentes funciones. Aunque a veces se ayudan de otros recursos estilísticos y retóricos, tales como la metáfora, las UFS pueden transmitir un contenido completo contextualizado en el discurso en que se insertan. Sin embargo, las UFS que se hallan en un discurso político no solo aparecen en ese lenguaje de especialidad; uno de los rasgos distintivos de esta categoría radica precisamente en la posibilidad de ubicarse en distintos contextos y discursos. Esta posibilidad estaría ligada a otro rasgo definitorio de las UFS en el discurso político: la utilización de UFS ayuda al político/a a conectar con el auditorio, pues en muchas ocasiones permite que el mensaje llegue de un modo mucho más accesible, lo cual fomenta la relación orador/ auditorio, lo que potencia, a su vez, la función apelativa. Así, el marco del discurso y la comunicación entre el/la dirigente político/a y el auditorio se centran en la base argumental en la que se fundamenta el discurso, propiciando la relación y conexión de las ideas transmitidas entre emisor y receptor. Como Messina Fajardo (2016: 125) establece:

Los políticos recurren a los fraseologismos, o a porciones de refranes disociados de su contexto o trastocados. Las estructuras lingǘsticas, al ser memorizadas y al pertenecer a la colectividad son reconocidas por todos sin necesidad de reproducir el texto completo. Esta es una técnica muy empleada también entre los clásicos de la literatura (Cervantes, Rojas, Lope, Quevedo). Con esta técnica, el discurso no solo gana rapidez, eficacia, sino [que] se establece una relación de convivencia y complicidad cultural con el interlocutor.

A raíz de esta afirmación, podemos comprobar que la multitud de funciones que las UFS pueden llegar a representar son ingentes. A propósito de lo establecido por Navarro (2002: 202-206), las UFS cumplen cuatro funciones 
diferentes: función lingüístico-textual, función fraseológica (citando a Zuluaga 1997: 631), función connotativa y, finalmente, función icónica. Así, se comprueba que las UFS persiguen sus propias finalidades dentro de los lenguajes de especialidad. Aunque las UFS pueden estudiarse bien como ejemplos de uso de la lengua general, bien como representaciones específicas de los lenguajes de especialidad, está claro que en lo que concierne al lenguaje político dichas funciones están bien delimitadas, puesto que básicamente cumplen con los mismos objetivos que persigue de principio a fin un discurso político: convencer mediante argumentos a su auditorio. En ese sentido, las UFS se utilizan en el lenguaje político como medios para facilitar la comprensión de los enunciados más complejos y para hacer llegar de un modo más cercano la idea transmitida al receptor. Lo que se consigue es que el receptor del mensaje capte a la perfección lo que el político/a intenta transmitir y, en el caso de las UFS más connotativas, se potencia una mayor conexión con el político/a dentro del hilo argumental perseguido en su discurso, gracias al empleo de UFS contextualizadas según cualidades diastráticas o diatópicas, lo que acerca al político/a a su destinatario.

\section{Expresiones y unidades fraseológicas y su presencia en el discurso político}

Para resumir brevemente la clasificación formal establecida por Corpas Pastor (1997: 51), de modo que con un simple vistazo podamos contextualizar el estado de la cuestión, proponemos el esquema recapitulativo que se ofrece a continuación (véase Figura I). En este punto, debemos decir que, si bien ha habido otras investigaciones posteriores que detallan algunos de los conceptos nombrados a continuación y establecen nuevas dicotomías y clasificaciones posibles (por ejemplo, la de Sevilla Muñoz \& Crida Álvarez 2013), decidimos abogar por las de esta autora por tratarse de la nomenclatura más utilizada y recurrente por la mayor parte de los expertos en el tema. En el cuadro recapitulativo posterior también se encontrará una clasificación que alude a unos criterios de división de carácter semántico, para lo cual hemos recurrido a las aportaciones de Luque Durán \& Manjón Pozas (2002: 2) y Montoro del Arco (2007: 131). Así, surgiría una clasificación semántica de 
las UFS que posibilitaría la existencia de dos subtipos: las UFS ontológicas y las culturales. En el caso de las ontológicas, hacen referencia a estructuras y unidades de naturaleza universal, ya que son extrapolables a todas las culturas; por su parte, las culturales se refieren a rasgos prototípicos de una sociedad o cultura en particular, y estarían en conexión con una de las funciones que comentamos con anterioridad (concretamente, la connotativa, en los términos de Navarro, op. cit.). Así lo explican los mismos autores (Durán \& Manjón Pozas, ut supra):

Como conclusión provisional, puede afirmarse que la tipología fraseológica tendría un esquema de partida en el cual existiría un planteamiento ontológico opuesto a un planteamiento cultural. El planteamiento ontológico postula que una parte de las metáforas no son más que maneras de hablar sobre un determinado fenómeno basándose en asociaciones ontológicas (fisiológicas, etc.) y, por tanto, tendrán un carácter universal. [...] Frente a las metáforas y a la fraseología de planteamiento ontológico existen las metáforas y la fraseología cultural, que se basan en algunas realidades peculiares de un pueblo y de una cultura, como es el caso de los toros en español, el béisbol en el mundo americano, el sumo en japonés, etc., aunque se podían citar centenares de ejemplos. Sin embargo, ontología y cultura son sólo los dos polos en la creación de fraseología metafórica. En realidad, al estudiar la fraseología de diferentes lenguas, encontramos muchos más hechos y problemas que hay que tener en cuenta y dilucidar antes de poder sentar las bases científicas de una tipología fraseológica.

Precisamente, en torno a las unidades fraseológicas culturales, Montoro del Arco (ibidem) explica que "La fraseología de las lenguas es uno de los medios a través de los cuales la memoria colectiva da cuenta de las cualidades y connotaciones socioculturales que se han ido asociando durante siglos [...]". Por ende, el estudio de este tipo de unidades (culturales) nos permite dar cuenta de que, en el contexto de esta investigación, una buena parte del legado lingüístico que destaca entre las UFS presentes en el discurso político es un fiel reflejo de la cultura y de la memoria social e histórica de una comunidad lingüística. 
1. Unidades fraseológicas (UFS)

a) Clasificación formal (Corpas Pastor, 1997)

- Locuciones (op. cit., 91):

- Locuciones nominales

- Locuciones adjetivas

- Locuciones adverbiales

- Locuciones verbales

- Locuciones prepositivas

- Locuciones conjuntivas

- Locuciones clausales

b) Colocaciones (op. cit., 66):

- Sustantivo + verbo

- Verbo + sustantivo

- Sustantivo + adjetivo/sustantivo

- Sustantivo + preposición + sustantivo

- Verbo + adverbio

- Adverbio + adjetivo

c) Enunciados fraseológicos:

- Paremias (op. cit., 147):

- Enunciados de valor específico

- Citas

- Refranes

- Fórmulas rutinarias (op. cit., 174)

- Fórmulas discursivas

- Fórmulas psicosociales

2. Clasificación semántica (Durán y Manjón Pozas, 2002: 2; Montoro del Arco, 2007: 131-132)

a) Ontológicas

b) Culturales

Figura I. Cuadro resumen recapitulativo de la clasificación formal y semántica de unidades fraseológicas (Corpas Pastor, 1997; Durán y Manjón, 2002; Montoro del Arco, 2007)

\section{Objetivos de nuestra investigación y metodología de trabajo}

Nuestro trabajo ha consistido en recopilar un corpus de veinte discursos políticos en inglés y otros veinte discursos políticos en francés que cuentan con sus respectivas traducciones oficiales hacia el español y hacia el inglés o francés (dependiendo de la lengua del TO). Los textos que componen el corpus son paralelos, lo cual implica que, además de contar con la versión original (en inglés o en francés, hallados en internet, periódicos, páginas web especializadas [previa comprobación con el original], traducciones oficiales 
en las páginas de la Embajada o de la UNESCO, etc.), también se ha dispuesto de la versión traducida correspondiente (en medios digitales, generalmente en la red de internet, en páginas especializadas en discurso político o directamente en medios de comunicación) ${ }^{2}$. El criterio que hemos seguido para seleccionar un discurso $\mathrm{u}$ otro de un mismo/a dirigente ha sido el de la temática del propio discurso, seleccionando especialmente discursos políticos institucionales, bien de índole nacional o internacional, ya que será en estos donde se registre una mayor frecuencia de terminología especializada, lo que implica, también, una mayor frecuencia de UFS de corte político. Para garantizar que las muestras eran similares en lo que concierne al tamaño, hemos utilizado discursos de una extensión similar, que podría equipararse con unos 10-15 minutos de duración en la oralidad, aproximadamente, como se ha comprobado en aquellos discursos de los que se ha encontrado una versión televisada a través del canal de internet Youtube. Además, solo se han contemplado discursos completos, no fragmentos ni noticias.

Dicho lo anterior, a continuación se indica la metodología de trabajo seguida, la cual ha sido dividida en tres fases:

a. Una primera fase, mediante la que se ha procedido a seleccionar cada una de las UFS halladas en los textos en inglés y en francés. Posteriormente, se compiló información relativa a cada una de estas unidades, utilizando para ello la ficha fraseológica que se mostrará posteriormente (véase Figura IV). Para la realización de dicha ficha, se utilizaron, en esta primera fase, obras lexicográficas en las que se ha basado por completo la fase de documentación de este trabajo, y que detallaremos ahora. El objetivo de esta primera fase consiste en compilar todas las UFS de los textos origen para buscar posteriormente una UF equivalente, teniendo en cuenta el contexto en lengua meta $^{3}$ (inglés/francés y español). Los resultados de esta primera fase nos han permitido elaborar un glosario con los datos obtenidos hasta el momento con nuestras propias propuestas de traducción, los cuales

2. Véase anexo final para más datos.

3. Se encontrarán, en este trabajo, alusiones al término "lengua meta" a través de la sigla "LM". De modo análogo, la sigla "LO" remitirá al término "lengua origen"; "TO", a "texto origen" y, finalmente, "TM" a "texto meta". 
se mostrarán en la parte final de este trabajo, así como conocer con gráficos porcentuales un conjunto de datos relativos al uso de las UFS en inglés y en francés en los discursos políticos que componen nuestro corpus. Esta contribución se centrará exclusivamente en esta primera fase.

b. Una segunda fase, mediante la que se ha comprobado en las traducciones de los TM si la traducción (oficial o en prensa) ofrece o no un equivalente formal y semántico apto para transmitir el mismo sentido que la UF del TO. Tras esto, se ha evaluado la pertinencia o inadecuación de dicha UF del TM a partir de los datos de nuestras fichas fraseológicas y de nuestro glosario, barajando también la posibilidad de la retroalimentación entre las diversas fuentes. Una vez valoradas todas las UFS, se dispondrán los resultados de forma porcentual igualmente, y se añadirán a nuestro glosario las UFS que se hayan traducido de un modo alternativo a nuestra propuesta, siempre que estén correctamente trasladadas con base en el contexto.

c. La fase final del proyecto se concibe a través de una herramienta lexicográfica que nos permitirá disponer de todo el glosario junto a las fichas fraseológicas en un portal web.

Incidiendo en la primera de estas tres fases, que es a la que nos dedicamos en este artículo, indicaremos que, en primer lugar, se seleccionaron las UFS que contenía cada discurso y se valoraron las dificultades de traducción asociadas al contexto específico en el que se proveía cada una de ellas. Tras un proceso de documentación extensivo, se buscaron decisiones traductológicas convenientes (lingüística y traductológicamente hablando) para representar la realidad a la que aludía la UF origen, respetando, en todo caso, el propósito fundamental que perseguía el orador del texto origen. Con posterioridad, se elaboró una ficha fraseológica para cada una de las UFS del corpus de trabajo, que ejemplificaremos posteriormente tomando como referencia el modelo presentado por Serrano Lucas (2010: 202). El contenido de estas fichas es crucial para este trabajo, ya que esta información será la que aparecerá al utilizar el motor de búsqueda del portal web donde aparecerán todas estas unidades para su consulta, una vez terminado el proyecto en su totalidad. 
Las fuentes empleadas a lo largo del proceso de documentación para proceder con nuestras propuestas de traducción han sido las siguientes:

\section{Fuentes documentales en inglés}

- Cambridge Advanced Learner's Dictionary. En papel

- Cambridge Phrasal Verbs Dictionary. En papel

- Collins Cobuild English Grammar. (2011). Bishopbriggs (Glasgow): HarperCollins

- Diccionario Cambridge en línea

- Diccionario Longman en línea

- Diccionario Merriam-Webster en línea

- Diccionario Oxford en línea

- Diccionario Oxford Inglés/Francés, Francés/Inglés (en papel)

- Diccionarios y glosarios de la Unión Europea (en línea): Lexicool

- Eurovoc: Tesauro multilingüe de la Unión Europea

- Gran Diccionario Oxford Inglés/Español, Español/Inglés (en papel)

- IATE: European Union Terminology Database. En línea

- Longman Dictionary of Contemporary English. (2005). Harlow: Pearson Education Limited

- Macmillan English Dictionary for Advanced Learners. (2007). Oxford: Macmillan

- Oxford Collocations Dictionary for students of English. En papel

- Oxford Idioms Dictionary for learners of English. En papel

- Oxford Phrasal Verbs for students of English. En papel

- Rigdom, J. (2018). Handbook of English Idioms, Parables and Colloquial Sayings. WordsRUs PhraseBooks, 1. Versión en línea

- The Free Dictionary. En línea

- Unbridged Dictionary Spanish/English, English/Spanish Larousse. En papel

\section{Fuentes documentales en francés}

- ABC Thesaurus (en línea)

- Cassagne, J.M et L. Nisset (2000). 101 French Idioms. Pennsylvania: McGraw-Hill

- Diccionario Larousse en línea

- Diccionario Oxford Inglés/Francés, Francés/Inglés (en papel)

- Diccionario Reverso en línea

- Gran Diccionario Larousse Español/Francés, Francés/Español (en papel)

- Gran Dictionnaire Anglais/Français, Français/Anglais Larousse (2017). En papel

- IATE: European Union Terminology Database. En línea

- Lexilogos (en línea)

- P. de Rieux, A. (2006): Dictionnaire des idiomes anglais et américains. Paris: Publibook 


\section{Fuentes documentales en español}

- Carbonell Basset, D. (1995). Diccionario fraseológico inglés/castellano, castellano/ inglés. Barcelona: Ediciones del Serbal

- Carbonell Basset, D. (2004). Diccionario inglés y español de modismos. Barcelona: Ediciones del Serbal

- Carbonell Basset, D. (2005). Nuevo diccionario de dichos y refranes actuales, inglés y castellano. Barcelona: Ediciones del Serbal

- Diccionario de la Real Academia Española (RAE, versión en línea). Disponible en este enlace

- Diccionario del Español Jurídico (DEJ) en línea

- Gran Diccionario Larousse de la Lengua Española

- Gran Diccionario Larousse Francés/Español, Español/Francés

- Gran Diccionario Oxford Inglés/Español, Español/Inglés (en papel)

- Seco, M. (2012). Nuevo diccionario de dudas y dificultades de la lengua. Madrid: Espasa

Figura II. Recapitulación de fuentes documentales para las propuestas de traducción en lengua meta

Tras resolver estos esquemas, elaboramos un glosario trilingüe centrado en discursos políticos, el cual será presentado en las páginas siguientes con el ánimo de facilitar las tareas de documentación en este lenguaje de especialidad a los traductores/as que se encuentren ante un reto traductológico que encaje dentro de las dimensiones de este trabajo.

En consonancia con todo lo anterior, los objetivos que se persiguen en este trabajo (tomando como referencia la primera fase a la que nos dedicaremos) son los que siguen:

- Compilar un corpus de trabajo compuesto por discursos políticos en inglés y francés para identificar todas las UFS dispuestas a lo largo de los mismos.

- Identificar todas las UFS halladas en el corpus en inglés y en el corpus en francés, con el fin de cuantificar el número estimado de UFS por pares de idiomas. Para llevar a cabo dicha identificación, se han seguido de cerca los criterios de clasificación de las obras lexicográficas mencionadas con anterioridad, además de nuestros propios conocimientos gramaticales en español y en lenguas extranjeras 
(inglés/francés) para proceder a identificarlas. No obstante, la ayuda de algunos programas específicos, tales como la herramienta Antconc, han servido de gran ayuda para identificar este tipo de unidades, con el objetivo de seleccionar aquellas cuya visibilidad en la totalidad del corpus fuera realmente representativa.

- Estudiar cada UF en el contexto específico de emisión en la lengua y cultura origen para comprender el significado adquirido en dicho contexto.

- Categorizar cada una de las UFS localizadas en el corpus de trabajo según la disposición de Corpas Pastor, Durán, Manjón Pozas \& Montoro del Arco (op. cit.), siguiendo el modelo de ficha fraseológica propuesto, con el fin de conocer cuál es el tipo de UFS más recurrente en los discursos políticos por cada par de lenguas.

\section{Traducir fraseología: las unidades fraseológicas del discurso político en inglés y en francés y su recepción en español en nuestro estudio}

\subsection{Corpus de trabajo}

En la elaboración del corpus se han seleccionado discursos de dirigentes políticos de diferentes organismos internacionales hasta naciones en particular. En este trabajo, las variantes que hemos introducido como criterios de búsqueda no han estado ligadas al estudio de los políticos/as per se, por lo que el único patrón diferenciador ha sido la lengua emitida, y no otros criterios como la ideología de cada orador/a político que pronuncia el discurso, la variable sexo, la variable edad, etc. Aunque estas aportan muchos datos a nuestro estudio, deberán quedarse relegadas a una futura investigación.

Siendo así, el corpus compilado adquiriría la forma siguiente: 


\begin{tabular}{|c|c|c|}
\hline $\begin{array}{l}\text { Número } \\
\text { discurso }\end{array}$ & $\begin{array}{c}\text { Discursos en inglés } \\
\text { (TO: EN) }\end{array}$ & $\begin{array}{c}\text { Discursos en francés } \\
\text { (TO: FR) }\end{array}$ \\
\hline 1 & Abraham Lincoln & Charles de Gaulle \\
\hline 2 & Barack Obama & Dominique de Villepin \\
\hline 3 & Bill Clinton & Édouard Philippe \\
\hline 4 & Boris Johnson & Emmanuel Macron \\
\hline 5 & Donald Trump & François Fillon \\
\hline 6 & Dwight Eisenhower & François Hollande \\
\hline 7 & Franklin D. Roosevelt & François Legault \\
\hline 8 & Geoffrey Howe & François Mitterrand \\
\hline 9 & George W. Bush & Georges Pompidou \\
\hline 10 & Harold Macmillan & Gautier Mignot \\
\hline 11 & John F. Kennedy & Jacques Chirac \\
\hline 12 & Margaret Thatcher & Jean Charest \\
\hline 13 & Mark Drakeford & Jean-Yves Le Dirian \\
\hline 14 & Martin Luther King & Laurent Fabius \\
\hline 15 & Nelson Mandela & Léon Blum \\
\hline 16 & Nikita Khrushchev & Marine Le Pen \\
\hline 17 & Robert F. Kennedy & Nicolas Sarkozy \\
\hline 18 & Ronald Reagan & Philippe Couillard \\
\hline 19 & Theresa May & Ueli Maurer \\
\hline 20 & Winston Churchill & Valéry Giscard d'Estaing \\
\hline
\end{tabular}

Figura III. Detalle del corpus de trabajo compilado atendiendo al autor (ordenado por orden alfabético)

\subsection{Muestra del procedimiento de análisis}

Tras compilar el corpus, la primera fase de trabajo consistía en identificar todas las UFS halladas a lo largo de los discursos. Después, había que contextualizar dicha UF en el contexto del acto comunicativo en el que se encuadraba, con el fin de apreciar correctamente el sentido en la lengua origen. Posteriormente, se llevó a cabo el proceso de documentación para localizar un equivalente en lengua meta, y por último, se procedió a realizar un proceso 
de revisión para comprobar si la traducción propuesta cumplía o no con las mismas expectativas del TO en lo referente a los fines de la traducción.

En las líneas siguientes, se ha incorporado una pequeña muestra esquemática donde señalaremos los aspectos a los que nos hemos referido anteriormente sobre las fases seguidas para llevar a cabo nuestra investigación. Dadas las constricciones espaciales, no nos será posible valorar una muestra por cada discurso que compone el corpus, así como tampoco un análisis extensivo de la totalidad de UFS del discurso, motivo por el cual tan solo esbozaremos aquí una muestra, escogida al azar para simplemente ejemplificar el modo de proceder en el análisis:

- Identificación del discurso:

- Nombre del emisor: Barack H. Obama

- Contexto del discurso: Discurso en El Cairo

- Fecha del discurso: 4 de junio de 2009

- Muestra:

(TO) ENGLISH

"But I am convinced that in order to move forward, we must say openly to each other the things we hold in our hearts and that too often are said only behind closed doors. There must be a sustained effort to listen to each other, tolearn from each other, to respect one another, and to seek common ground. As the Holy Qur'an tells us, 'Be conscious of God and speak always the truth.' That is what I will try to do today, to speak the truth as best I can, humbled by the task before us, and firm in my belief that the interests we share as human beings are far more powerful than the forces that drive us apart".

- Valoraciones: En primer lugar, se han identificado las UFS del discurso halladas en el fragmento. Como podemos ver, no todas pertenecen al mismo nivel, si contemplamos el cuadro recapitulativo de Corpas Pastor (ut supra); así, nos encontramos con colocaciones, como por ejemplo move forward, human beings o drive us apart, y también con paremias, del tipo de Be conscious of God and speak always the truth, además de locuciones de diversa índole, como por ejemplo in order to. Tras considerar el contenido semántico y pragmático en el que se inserta este fragmento, llevaríamos a cabo una fase de comprensión semántica de lo que dicha UF quiere comunicar al lector desde el punto de vista del plano ilocutivo, al lector. Por ejemplo, la expresión Be 
conscious of God and speak always the truth se ubicaría en un contexto en el que el político/a quiere utilizar una paremia para ilustrar el mensaje que está transmitiendo al auditorio (escucharse mutuamente, haciendo alusión especialmente a las naciones reunidas en la cumbre en la que se encuentra), por lo que se ayuda de esta UF estratégicamente seleccionada, ya que, existiendo otras tantas UFS de significado semejante, escoge una que procede del libro sagrado para el auditorio que tiene delante, puesto que se encuentra en El Cairo: El Corán. Esto añade significado inferido al mensaje transmitido. Por ende, desde el punto de vista semántico, nos encontraríamos frente a una UF de carácter cultural. Esto incluye una puntualización para el traductor: dicha expresión tiene una traducción acuñada, que ya procede de un libro que ha sido traducido a muchas lenguas. Esta UF en concreto se ha traducido en bastantes versiones del libro original por "Tengan conciencia de Dios y digan siempre la verdad" en español, y por "Sois conscients de Dieu et dis toujours la vérité" en francés, traducción que se corresponde con la versión más habitual en este libro sagrado para cada una de estas lenguas, respectivamente, y que incluye, además, una nueva UF: "tener conciencia de" y "être conscient de". En este último ejemplo, sería la versión en francés la más próxima formalmente a la versión en inglés, ya que respeta la estructura verbo ser + adjetivo + preposición de, mientras que en español se procede a una transposición (en términos de Hurtado, 2001) mediante la que se utiliza el sustantivo de la misma familia léxica a la que pertenece el adjetivo correspondiente: conciencia. En cuanto a las funciones que llevaría a cabo la UF que nos ocupa, diremos que cumple con las funciones de Navarro (ut supra): la función fraseológica, en tanto que este fragmento está plagado de UFS utilizadas para transmitir mejor el mensaje al auditorio, receptor del mensaje comunicado; la connotativa, en tanto que se sirve de expresiones comunes al ámbito cultural del receptor del mensaje; y, finalmente, icónica, en tanto que dicho pasaje es un ejemplo característico de lenguaje metafórico y de la función poética, utilizada para ilustrar el argumento argüido a lo largo del fragmento. 


\section{- Ficha fraseológica (EN/FR/ES):}

\begin{tabular}{|c|c|}
\hline \multicolumn{2}{|c|}{$\begin{array}{c}\text { Unidad fraseológica en LO (EN) } \\
\text { Behind closed doors }\end{array}$} \\
\hline Fuente del TO & TO: EN. Discurso 2 \\
\hline Definición & $\begin{array}{c}\text { 'If something happens behind closed doors, } \\
\text { it is hidden or kept secret from public } \\
\text { view' }\end{array}$ \\
\hline Fuente de la definición & $\begin{array}{c}\text { Diccionario Cambridge en línea. } \\
\text { Disponible en este enlace }\end{array}$ \\
\hline Tipo de UF & Locución adverbial \\
\hline $\begin{array}{c}\text { Ejemplo de uso de la UF en LO } \\
\text { Fuente }\end{array}$ & $\begin{array}{l}\text { [...] we must say openly to each other } \\
\text { the things we hold in our hearts and that } \\
\text { too often are said only behind closed doors } \\
\text { TO: EN. Discurso } 2\end{array}$ \\
\hline \multicolumn{2}{|c|}{ Observaciones } \\
\hline $\begin{array}{l}\text { - Tema/Campo semántico: Negociac } \\
\text { - Variantes en LO: Behind shut door } \\
\text { - Sinónimos: In privacy; be shroudec } \\
\text { keep something just between you a } \\
\text { - } \text { Antónimos: Openly; Publicly; Fam } \\
\text { - } \text { Registro: Formal e informal. En est } \\
\text { - Pertenencia a lenguajes de especia } \\
\text { dadas las relaciones legales, jurídic } \\
\text { políticas secretas a las que el públic } \\
\text { ocasiones, ni siquiera se le informa } \\
\text { - Grado de creatividad metafórica: } \\
\text { interpretación cognitiva. Esta UF h } \\
\text { para indicar, a través de dicha metá } \\
\text { tener acceso de forma fácil. Solo lo } \\
\text { tendrán acceso a la información pri } \\
\text { - Fuentes: Diccionarios Longman, C }\end{array}$ & $\begin{array}{l}\text { privadas; secretismo, privacidad } \\
\text { ecrecy/mystery; take sb to one side; to } \\
\text { le; in camera; in chambers } \\
\text { y; Commonly } \\
\text { texto, formal } \\
\text { l: Jurisdicción, legalidad, discurso político, } \\
\text { nstitucionales y los encuentros y reuniones } \\
\text { puede tener acceso y de las que, en } \\
\text { mantener así el anonimato } \\
\text { : existencia de metáfora, pero con fácil } \\
\text { eferencia a la imagen de una puerta cerrada } \\
\text { que se trata de algo a lo que no se puede } \\
\text { pueden "atravesar esa puerta" son los que } \\
\text { iada } \\
\text { idge y Oxford (versión en línea). }\end{array}$ \\
\hline
\end{tabular}




\begin{tabular}{|c|c|}
\hline \multicolumn{2}{|c|}{$\begin{array}{c}\text { Unidad fraseológica en lengua meta (ES) } \\
\text { Detrás de puertas cerradas }\end{array}$} \\
\hline Fuente del término meta & $\begin{array}{l}\text { Gran Diccionario Oxford Español/Inglés, } \\
\text { Inglés/Español (2008) (versión en papel) }\end{array}$ \\
\hline Definición & $\begin{array}{l}\text { 'Dicho de un juicio o de una vista: Que } \\
\text { se desarrolla, por motivos de honestidad, } \\
\text { orden público y otros análogos, en } \\
\text { presencia solo de las partes, sus } \\
\text { representantes y sus defensas' }\end{array}$ \\
\hline Fuente de la definición & RAE en línea. Disponible en este enlace \\
\hline $\begin{array}{c}\text { Ejemplo de uso de la UF en LM } \\
\text { Fuente }\end{array}$ & $\begin{array}{l}\text { El proceso en materia de transparencia } \\
\text { y acceso del público a los documentos } \\
\text { durante mucho tiempo se ha } \\
\text { desarrollado detrás de puertas cerradas } \\
\text { herméticamente. } \\
\text { Debate del Parlamento Europeo. Enlace }\end{array}$ \\
\hline \multicolumn{2}{|c|}{ Observaciones } \\
\hline \multicolumn{2}{|c|}{$\begin{aligned} & \text { - Tipo de correspondencia: Locución adverbial. La traducción se mantiene, tanto en } \\
& \text { la forma como en el sentido. Correspondencia formal y conceptual } \\
& \text { - Tema/Campo semántico: Legal, jurídico, político } \\
& \text { - } \text { Variantes en LO: A puerta cerrada; a puertas cerradas } \\
& \text { - Sinónimos: Secretamente; subrepticiamente; de forma secreta; en privado; de } \\
& \text { forma confidencial; a solas; en secreto; extraoficialmente; reservadamente } \\
& \text { - Antónimos: Abiertamente; públicamente; manifiestamente; oficialmente } \\
& \text { - } \text { Registro: Formal e informal. En este contexto, formal } \\
& \text { - Pertenencia a lenguajes de especialidad: Similares a los de la lengua origen } \\
& \text { - Grado de creatividad metafórica: Similar al de la lengua origen } \\
& \text { - Fuentes: RAE; Diccionario Reverso en línea; Diccionario del Español Jurídico } \\
& \text { (DEJ) en línea; Gran Diccionario Oxford Inglés/Español, Español/Inglés (en papel) }\end{aligned}$} \\
\hline \multicolumn{2}{|c|}{$\begin{array}{l}\text { Unidad fraseológica en lengua meta (FR) } \\
\text { Derrière des portes fermées }\end{array}$} \\
\hline Fuente del término meta & $\begin{array}{c}\text { Diccionario Oxford Inglés/Francés, } \\
\text { Francés/Inglés (en papel) }\end{array}$ \\
\hline Definición & $\begin{array}{l}\text { 'Débats judiciaires hors de la présence du } \\
\text { public. (Le huis clos peut être ordonné } \\
\text { par le juge lorsque les débats présentent } \\
\text { un danger pour l'ordre public ou les } \\
\text { bonnes mœurs)' }\end{array}$ \\
\hline
\end{tabular}




\begin{tabular}{|c|c|}
\hline Fuente de la definición & Diccionario Larousse \\
\hline Ejemplo de uso de la UF en LM & $\begin{array}{c}\text { Enfin, nous assistons ici, non à processus } \\
\text { constitutionnel démocratique, mais à un } \\
\text { jeu de pouvoirs qui se déroule derrière } \\
\text { des portes fermées. }\end{array}$ \\
\hline & Debate del Parlamento Europeo. Enlace \\
\hline \multicolumn{2}{|c|}{ vaciones } \\
\hline \multicolumn{2}{|c|}{$\begin{array}{l}\text { - Tipo de correspondencia: Locución adverbial. La traducción se mantiene, tanto en } \\
\text { la forma como en el sentido. Correspondencia formal y conceptual } \\
\text { _ } \text { Tema/Campo semántico: Legal, jurídico, político } \\
\text { - Variantes en LO: Á portes fermées } \\
\text { - Sinónimos: À huis clos; toutes portes fermées; sans que le public soit admis; en } \\
\text { petit comité; en secret } \\
\text { - Antónimos: Publiquement; officiellement; de manière manifeste; partager des } \\
\text { informations; communautairement; sans restriction } \\
\text { - Registro: Formal e informal. En este contexto, formal } \\
\text { - Pertenencia a lenguajes de especialidad: Similares a los de la lengua origen } \\
\text { - Grado de creatividad metafórica: Similar al de la lengua origen } \\
\text { - Fuentes: } \\
\text { P. de Rieux, A. (2006): Dictionnaire des idiomes anglais et américains. Paris: } \\
\text { Publibook, p. 50. } \\
\text { Diccionario Larousse; Lexilogos; ABC Thesaurus; Diccionario Reverso en línea; } \\
\text { Diccionario Oxford Inglés/Francés, Francés/Inglés (en papel) }\end{array}$} \\
\hline
\end{tabular}

Figura IV. Modelo de ficha fraseológica (EN, FR, ES) siguiendo el modelo propuesto en Serrano Lucas (ut supra)

\section{Resultados del análisis}

Tras llevar a cabo un extenso análisis, con una fase analítica similar a la que hemos esbozado en la muestra, pero con la totalidad de discursos que componen el corpus y ahondando más en las características lingüísticas que definen a las UFS, hemos obtenido los resultados siguientes: 
- Uso de UFS por cada lengua de trabajo

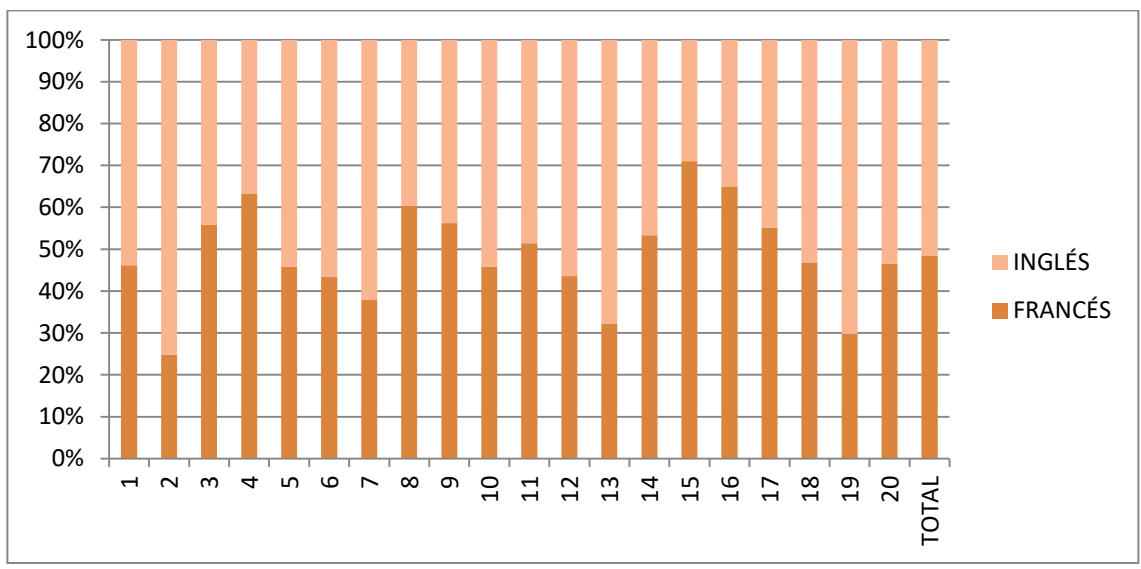

Figura V. Uso de las UFS por cada lengua de trabajo (EN, FR)

- Porcentaje de uso referido a las locuciones, colocaciones y paremias

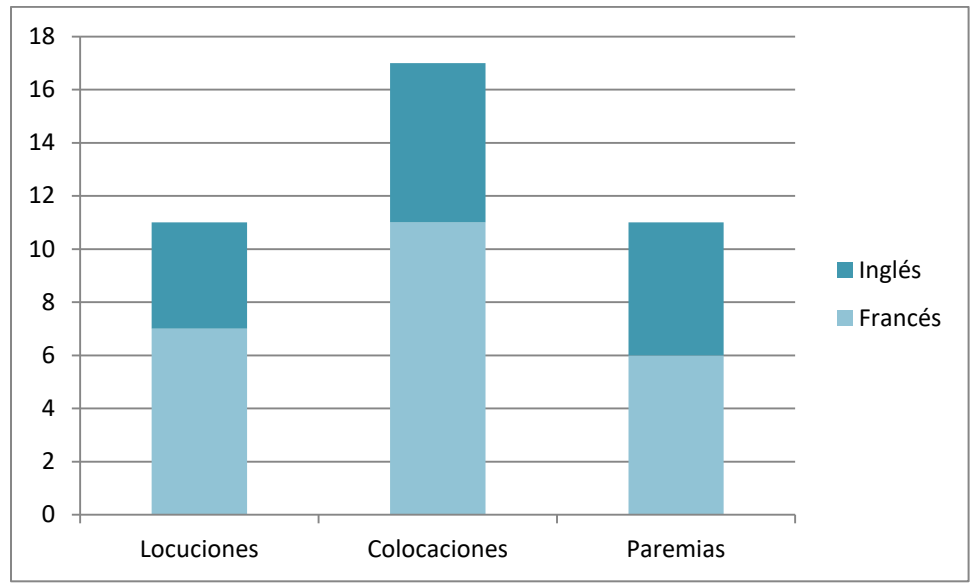

Figura VI. Uso de locuciones, colocaciones y paremias (EN, FR) 
- Porcentaje relativo al nivel semántico de las UFS: ontológicas o culturales

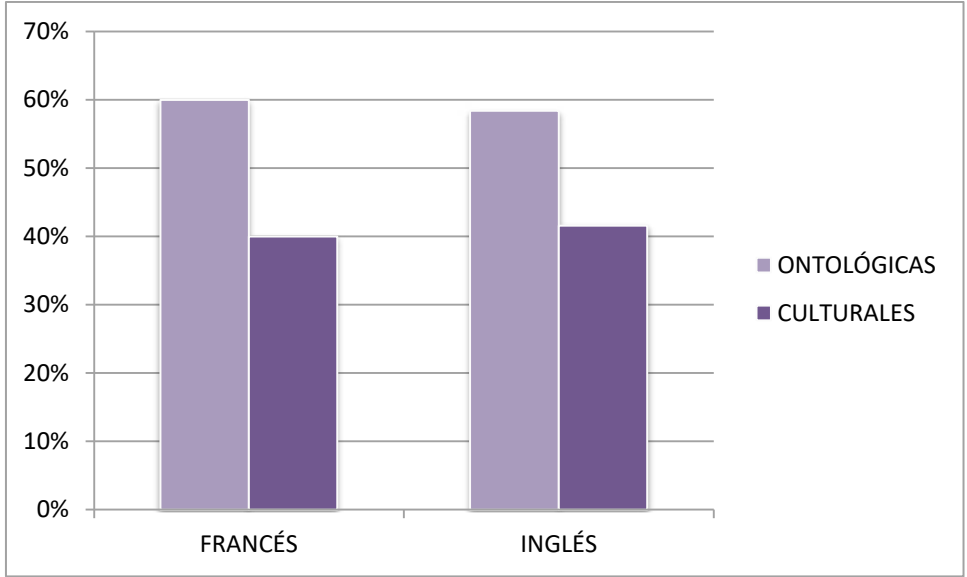

Figura VII. UFS relativas al nivel semántico (EN, FR)

\section{Propuesta de glosario trilingüe de unidades fraseológicas halladas en discursos políticos (EN, FR, ES)}

El análisis llevado a cabo en esta investigación nos ha permitido delimitar una búsqueda documental muy amplia, con el fin de valorar la cantidad de UFS resultantes del corpus en EN y en FR compilado, para este trabajo y proceder con la búsqueda de una solución traductológica apropiada para las lenguas metas correspondientes. La utilización de fichas fraseológicas ha facilitado el análisis de cada una de las UFS objeto de estudio, y ha simplificado la tarea de documentación para la disposición del glosario trilingüe final. Antes de entrar en materia, nos gustaría aclarar que existen, en muchos casos, otras opciones posibles de traducción aplicadas a otros contextos, pero la propuesta que hemos añadido en esta ocasión está adaptada, según nuestro mejor criterio, al marco comunicativo del texto origen de donde procede cada UF. En cuanto a la clasificación formal de estas, como podrá comprobarse, se han seguido de cerca los criterios expuestos con anterioridad de Corpas Pastor 
(1997), Durán y Manjón (2002) y Montoro del Arco (2007). Ese ha sido el principio seguido para incluir las UFS que componen el corpus de trabajo. De este modo, podrán encontrarse principalmente todos aquellos paradigmas o modelos de UFS que se conciben como colocaciones (con modelos de colocación que siguen cualquiera de los patrones anteriormente mencionados, tales como: verbo + sintagma nominal (porter des risques, por ejemplo); verbo + sintagma preposicional, (to die in vain); locuciones (por ejemplo, en lo referente a, cuyo equivalente en francés [TO] sería à l'égard de, y cuya propuesta de traducción al inglés sería la de with regard to); unidades fraseológicas ontológicas y culturales (the House of Commons, por ejemplo). Este término supone un ejemplo de unidad terminológica indisociable, puesto que la realidad a la que alude carecería de sentido si se separaran cualquiera de los dos términos que la componen esta unidad. Además, forma parte de una realidad establecida culturalmente, ya que hace referencia a un término propio de la jurisdicción y política de Reino Unido, por lo que el propio término ya ayuda a contextualizar la cultura origen. Una vez terminada la investigación, se dispondrán todas las UFS (fichas fraseológicas y glosario) en un portal web que permitirá acceder a toda la información formal y semántica, así como a las diferentes propuestas de traducción (directa e inversa) de cada una de estas unidades, con la posibilidad de acceder a ellas mediante diferentes criterios de búsqueda. Como ya justificamos con anterioridad, por cuestiones de espacio no nos será posible detallar todas y cada una de las UFS localizadas en el corpus de trabajo, por lo que tan solo se han dispuesto aquellas que suscitan mayor interés y con una frecuencia de repetición más alta. Las UFS y las traducciones hacia los otros dos idiomas proceden de nuestro corpus de trabajo trilingüe. 


\begin{tabular}{|c|c|c|c|}
\hline $\begin{array}{l}\text { Término en } \\
\text { INGLÉS } \\
(\mathrm{EN})\end{array}$ & $\begin{array}{l}\text { Fuente } \\
\text { (TO) }\end{array}$ & $\begin{array}{c}\text { Término en } \\
\text { FRANCÉS } \\
\text { (FR) }\end{array}$ & $\begin{array}{c}\text { Término en } \\
\text { ESPAÑOL } \\
\text { (ES) }\end{array}$ \\
\hline A call to bear arms & EN-11 & $\begin{array}{c}\text { Un appel à porter les } \\
\text { armes }\end{array}$ & $\begin{array}{c}\text { Pedir que se } \\
\text { levanten las armas }\end{array}$ \\
\hline A failure of will & EN-18 & Manque de volonté & Falta de voluntad \\
\hline A new birth of freedom & EN-1 & Une nouvelle liberté & $\begin{array}{c}\text { Un nuevo concepto } \\
\text { de libertad }\end{array}$ \\
\hline All over again & EN-3 & Encore une fois & De nuevo \\
\hline Along with our allies & EN-6 & $\begin{array}{l}\text { Une collaboration } \\
\text { avec nos alliés }\end{array}$ & $\begin{array}{c}\text { Junto a nuestros } \\
\text { aliados }\end{array}$ \\
\hline At the forefront of & EN-2 & À l'avant-garde & Al frente \\
\hline At the highest level & EN-9 & Au plus haut niveau & Al máximo \\
\hline Behind closed doors & EN-2 & $\begin{array}{c}\text { Derrière des portes } \\
\text { fermées }\end{array}$ & $\begin{array}{l}\text { Detrás de puertas } \\
\text { cerradas }\end{array}$ \\
\hline $\begin{array}{l}\text { Beyond a shadow of a } \\
\text { doubt }\end{array}$ & EN-3 & Sans aucun doute & Sin lugar a dudas \\
\hline By our presence & EN-7 & Avec notre présence & $\begin{array}{c}\text { Con nuestra } \\
\text { presencia }\end{array}$ \\
\hline Cold War & EN-16 & Guerre Froide & Guerra Fría \\
\hline Common ground & EN-2 & Un terrain d'entente & $\begin{array}{c}\text { Punto de vista } \\
\text { común }\end{array}$ \\
\hline Drive someone's apart & EN-2 & $\begin{array}{c}\text { Mettre quelqu'un à } \\
\text { l'Écarte }\end{array}$ & Apartar a alguien \\
\hline Each day since & EN-5 & Chaque jour depuis & $\begin{array}{c}\text { Cada día desde } \\
\text { entonces }\end{array}$ \\
\hline Ever since & EN-1 & Dès lors & Desde entonces \\
\hline Follow the Constitution & $\mathrm{EN}-2$ & $\begin{array}{l}\text { Respecter la } \\
\text { Constitution }\end{array}$ & $\begin{array}{l}\text { Respetar la } \\
\text { Constitución }\end{array}$ \\
\hline For over a & EN-2 & Pour plus de & Durante más de un \\
\hline $\begin{array}{c}\text { For the last days/ } \\
\text { centuries }\end{array}$ & EN-6 & $\begin{array}{c}\text { Pour les derniers } \\
\text { jours/siècles }\end{array}$ & $\begin{array}{c}\text { Durante los últimos } \\
\text { días/siglos }\end{array}$ \\
\hline God bless America & EN-3 & $\begin{array}{l}\text { Dieu bénisse } \\
\text { l'Amérique }\end{array}$ & $\begin{array}{l}\text { Dios bendiga } \\
\text { América }^{4}\end{array}$ \\
\hline
\end{tabular}

4. En español, se ha registrado una frecuencia mayor para traducir esta expresión protocolaria característica del epílogo del discurso por "Dios bendiga América". Sin embargo, debemos tener en cuenta que aunque se trata de la expresión probablemente más 


\begin{tabular}{|c|c|c|c|}
\hline God bless you & EN-3 & Dieu vous bénisse & Dios te bendiga \\
\hline House of Commons & EN-4 & $\begin{array}{l}\text { Chambre des } \\
\text { communes }\end{array}$ & $\begin{array}{l}\text { Cámara de los } \\
\text { Comunes }\end{array}$ \\
\hline Human beings & EN-2 & Êtres humains & Seres humanos \\
\hline In my belief & EN-2 & Selon moi & En mi opinión \\
\hline In the aftermath & EN-12 & Par la suite & Después de esto \\
\hline In the heights of victory & EN-5 & $\begin{array}{l}\text { Au sommet de la } \\
\text { victoire }\end{array}$ & $\begin{array}{c}\text { En la cumbre de la } \\
\text { victoria }\end{array}$ \\
\hline In their heart of hearts & EN-12 & $\begin{array}{l}\text { Au fond de leur } \\
\text { coeur }\end{array}$ & $\begin{array}{l}\text { En el fondo (de su } \\
\text { corazón) }\end{array}$ \\
\hline It is no coincidence that & EN-18 & $\begin{array}{l}\text { Ce n'est pas une } \\
\text { coïncidence que }\end{array}$ & $\begin{array}{l}\text { No es ninguna } \\
\text { coincidencia que }\end{array}$ \\
\hline $\begin{array}{l}\text { Let (me/us) begin } \\
\text { (tonight/today) by }\end{array}$ & EN-18 & $\begin{array}{l}\text { Commencer (ce soir/ } \\
\text { aujourd'hui) par }\end{array}$ & $\begin{array}{c}\text { Avanzar/Ponerse en } \\
\text { marcha }\end{array}$ \\
\hline Let (us) go forth to & EN-11 & Aller vers/Avancer & Centrémonos en \\
\hline $\begin{array}{l}\text { March to the tune of } \\
\text { pressure groups }\end{array}$ & EN-2 & $\begin{array}{c}\text { Marcher au rythme } \\
\text { des groupes de } \\
\text { pression }\end{array}$ & $\begin{array}{l}\text { Seguir de cerca } \\
\text { a los grupos de } \\
\text { presión }\end{array}$ \\
\hline Nuclear attack & EN-2 & Attaque nucléaire & Ataque nuclear \\
\hline Open mind & EN-15 & Esprit ouvert & Mente abierta \\
\hline Out of secondary & EN-7 & Aller droit au but & Ir al grano \\
\hline Outside the stockade & EN-4 & $\begin{array}{c}\text { En dehors de la } \\
\text { palissade }\end{array}$ & Salir de la estacada \\
\hline Tax burden & EN-18 & Charge fiscale & Carga fiscal \\
\hline The American dream & EN-5 & Le rêve américain & El sueño americano \\
\hline The best I can & EN-2 & $\begin{array}{l}\text { Le mieux que je } \\
\text { puisse faire }\end{array}$ & Lo mejor que pueda \\
\hline $\begin{array}{l}\text { The direction we want to } \\
\text { move in }\end{array}$ & EN-16 & $\begin{array}{l}\text { La direction dans } \\
\text { laquelle nous } \\
\text { voulons aller }\end{array}$ & $\begin{array}{c}\text { Es a donde } \\
\text { queremos llegar }\end{array}$ \\
\hline The mounting arms race & EN-16 & $\begin{array}{l}\text { La course aux } \\
\text { armements }\end{array}$ & $\begin{array}{c}\text { La carrera } \\
\text { armamentista }\end{array}$ \\
\hline
\end{tabular}

extendida, en realidad el término en inglés "America", en este caso, considerando en todo momento el contexto de los discursos del corpus, se refiere a los "Estados Unidos" como país y no a "América" como continente. 


\begin{tabular}{|c|c|c|c|}
\hline $\begin{array}{l}\text { The need will be upon } \\
\text { us fast }\end{array}$ & EN-4 & Le besoin sera vite là & $\begin{array}{c}\text { La necesidad caerá } \\
\text { sobre nosotros } \\
\text { rápidamente }\end{array}$ \\
\hline $\begin{array}{l}\text { The pain falls drop by } \\
\text { drop upon the heart }\end{array}$ & EN-17 & $\begin{array}{l}\text { La douleur tombe } \\
\text { goutte à goutte sur } \\
\text { le couur }\end{array}$ & $\begin{array}{c}\text { El dolor cae gota } \\
\text { a gota sobre el } \\
\text { corazón }\end{array}$ \\
\hline The tactics of terror & EN-9 & $\begin{array}{c}\text { Les tactiques de la } \\
\text { terreur }\end{array}$ & $\begin{array}{l}\text { Las tácticas del } \\
\text { terror }\end{array}$ \\
\hline The Taliban regime & EN-9 & Le régime Taliban & El régimen talibán \\
\hline $\begin{array}{c}\text { The trumpet summons } \\
\text { us again }\end{array}$ & EN-11 & $\begin{array}{l}\text { La trompette nous } \\
\text { convoque à nouveau }\end{array}$ & $\begin{array}{c}\text { Ya suenan de nuevo } \\
\text { los tambores }\end{array}$ \\
\hline There is no doubt & EN-2 & Il n'y a aucun doute & No cabe duda \\
\hline $\begin{array}{l}\text { To achieve political } \\
\text { emancipation }\end{array}$ & EN-2 & $\begin{array}{c}\text { Parvenir à } \\
\text { l'émancipation } \\
\text { politique }\end{array}$ & $\begin{array}{c}\text { Lograr la } \\
\text { emancipación } \\
\text { política }\end{array}$ \\
\hline To be created equal & EN-1 & Être crée égal & Ser iguales \\
\hline To be honoured to be & EN-2 & $\begin{array}{c}\text { Avoir l'honneur } \\
\text { d'être }\end{array}$ & Es un honor... \\
\hline $\begin{array}{l}\text { To be imposed upon (one } \\
\text { nation) }\end{array}$ & EN-2 & $\begin{array}{c}\text { Être imposé à (une } \\
\text { nation) }\end{array}$ & $\begin{array}{c}\text { Imponerse a (una } \\
\text { nación) }\end{array}$ \\
\hline To be in a fight & EN-9 & 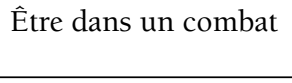 & $\begin{array}{c}\text { Estar en medio de } \\
\text { una pugna }\end{array}$ \\
\hline To be made in peacetime & EN-12 & $\begin{array}{c}\text { Être fait en temps } \\
\text { de paix }\end{array}$ & $\begin{array}{l}\text { Hacer algo en } \\
\text { tiempos de paz }\end{array}$ \\
\hline To be put on notice & EN-9 & Être mis en garde & $\begin{array}{l}\text { Ser informado de } \\
\text { algo }\end{array}$ \\
\hline $\begin{array}{l}\text { To be singled out for } \\
\text { unfair treatment }\end{array}$ & EN-9 & $\begin{array}{c}\text { Être distingué } \\
\text { pour un traitement } \\
\text { inéquitable }\end{array}$ & $\begin{array}{l}\text { Ser señalado por un } \\
\text { trato injusto }\end{array}$ \\
\hline To become a Democrat & EN-9 & Devenir démocrate & Hacerse demócrata \\
\hline To breed fear & EN-10 & Susciter la peur & Promover el miedo \\
\hline To cause grave danger & EN-8 & $\begin{array}{l}\text { Causer un grave } \\
\text { danger }\end{array}$ & $\begin{array}{l}\text { Causar un grave } \\
\text { peligro }\end{array}$ \\
\hline To combat malaria & EN-15 & $\begin{array}{c}\text { Lutter contre le } \\
\text { paludisme }\end{array}$ & Combatir la malaria \\
\hline $\begin{array}{l}\text { To comply with EU } \\
\text { regulations }\end{array}$ & EN-4 & $\begin{array}{l}\text { Se conformer aux } \\
\text { règlements de l'UE }\end{array}$ & $\begin{array}{c}\text { Respetar la } \\
\text { legislación de la UE }\end{array}$ \\
\hline $\begin{array}{l}\text { To curb the size and } \\
\text { influence of }\end{array}$ & EN-3 & $\begin{array}{l}\text { Réduire la taille et } \\
\text { l'influence des }\end{array}$ & $\begin{array}{l}\text { Reducir el tamaño } \\
\text { y la influencia de }\end{array}$ \\
\hline
\end{tabular}




\begin{tabular}{|c|c|c|c|}
\hline To develop procedures & EN-1 & $\begin{array}{c}\text { Développer des } \\
\text { procédures }\end{array}$ & $\begin{array}{c}\text { Desarrollar } \\
\text { procedimientos }\end{array}$ \\
\hline To die in vain & EN-15 & Décéder en vain & Morir en vano \\
\hline To each other & $\mathrm{EN}-2$ & $\begin{array}{c}\text { Les uns envers les } \\
\text { autres }\end{array}$ & Entre nosotros \\
\hline $\begin{array}{l}\text { To embark on the } \\
\text { consideration }\end{array}$ & EN-12 & Entamer la réflexion & $\begin{array}{c}\text { Llegar a considerar } \\
\text { algo }\end{array}$ \\
\hline $\begin{array}{c}\text { To engage in violence } \\
\text { against }\end{array}$ & EN-3 & $\begin{array}{l}\text { S'engager dans la } \\
\text { violence contre }\end{array}$ & $\begin{array}{c}\text { Promover/Ejercer la } \\
\text { violencia contra }\end{array}$ \\
\hline $\begin{array}{l}\text { To expand health care } \\
\text { coverage }\end{array}$ & EN-14 & $\begin{array}{c}\text { Étendre la } \\
\text { couverture des soins } \\
\text { de santé }\end{array}$ & $\begin{array}{c}\text { Ampliar la } \\
\text { cobertura en } \\
\text { materia de salud }\end{array}$ \\
\hline $\begin{array}{c}\text { To experience the } \\
\text { oppression of }\end{array}$ & EN-9 & $\begin{array}{c}\text { Faire l'expérience de } \\
\text { l'oppression des }\end{array}$ & $\begin{array}{c}\text { Experimentar la } \\
\text { opresión de }\end{array}$ \\
\hline To forge a grand alliance & EN-20 & $\begin{array}{c}\text { Forger une grande } \\
\text { alliance }\end{array}$ & $\begin{array}{c}\text { Forjar una gran } \\
\text { alianza }\end{array}$ \\
\hline $\begin{array}{l}\text { To form a new } \\
\text { administration }\end{array}$ & EN-16 & $\begin{array}{l}\text { Former une nouvelle } \\
\text { administration }\end{array}$ & $\begin{array}{c}\text { Consolidar } \\
\text { una nueva } \\
\text { administración }\end{array}$ \\
\hline $\begin{array}{l}\text { To go beyond these } \\
\text { rather difficult times }\end{array}$ & EN-3 & $\begin{array}{l}\text { Aller au-delà de } \\
\text { ces temps plutôt } \\
\text { difficiles }\end{array}$ & $\begin{array}{l}\text { Superar estos } \\
\text { tiempos tan } \\
\text { difíciles } \\
\end{array}$ \\
\hline To go into politics & EN-3 & Faire de la politique & Entrar en política \\
\hline $\begin{array}{l}\text { To joke someone's only } \\
\text { purpose }\end{array}$ & EN-10 & $\begin{array}{l}\text { Plaisanter sur le seul } \\
\text { but de quelqu'un }\end{array}$ & $\begin{array}{c}\text { Burlarse del } \\
\text { propósito de } \\
\text { alguien }\end{array}$ \\
\hline To keep in mind & EN-11 & Ne pas oublier que & Tener en cuenta \\
\hline $\begin{array}{l}\text { To look back on the } \\
\text { victory }\end{array}$ & EN-12 & $\begin{array}{c}\text { Se souvenir de la } \\
\text { victoire }\end{array}$ & Recordar la victoria \\
\hline $\begin{array}{c}\text { To look the urgency of } \\
\text { the moment }\end{array}$ & EN-11 & $\begin{array}{c}\text { Valoir l'urgence du } \\
\text { moment }\end{array}$ & $\begin{array}{c}\text { Valorar la urgencia } \\
\text { del momento }\end{array}$ \\
\hline To lose the ability & EN-11 & Perdre la capacité & Perder la capacidad \\
\hline $\begin{array}{l}\text { To lose the institutional } \\
\text { memory }\end{array}$ & EN-13 & $\begin{array}{c}\text { Perdre la mémoire } \\
\text { institutionnelle }\end{array}$ & $\begin{array}{c}\text { Perder la memoria } \\
\text { institucional }\end{array}$ \\
\hline $\begin{array}{c}\text { To meet in the aftermath } \\
\text { of }\end{array}$ & EN-2 & $\begin{array}{l}\text { Se rencontrer à la } \\
\text { suite de }\end{array}$ & $\begin{array}{l}\text { Reunirse después } \\
\text { de }\end{array}$ \\
\hline To move forward & $\mathrm{EN}-2$ & Avancer & $\begin{array}{c}\text { Mirar hacia } \\
\text { adelante }\end{array}$ \\
\hline To promote peace & EN-11 & Promouvoir la paix & Fomentar la paz \\
\hline
\end{tabular}




\begin{tabular}{|c|c|c|c|}
\hline To rejoice at our success & EN-9 & $\begin{array}{l}\text { Se réjouir de notre } \\
\text { succès }\end{array}$ & $\begin{array}{l}\text { Alegrarse de los } \\
\text { éxitos }\end{array}$ \\
\hline $\begin{array}{c}\text { To renew the pledge of } \\
\text { support }\end{array}$ & EN-7 & $\begin{array}{c}\text { Renouveler la } \\
\text { promesse de soutien }\end{array}$ & $\begin{array}{c}\text { Renovar la promesa } \\
\text { de apoyo }\end{array}$ \\
\hline $\begin{array}{l}\text { To respect someone's } \\
\text { faith }\end{array}$ & EN-12 & $\begin{array}{c}\text { Respecter la foi de } \\
\text { quelqu'un }\end{array}$ & $\begin{array}{l}\text { Respetar la fe de } \\
\text { alguien }\end{array}$ \\
\hline $\begin{array}{c}\text { To stand as a beacon of } \\
\text { hope }\end{array}$ & EN-2 & $\begin{array}{c}\text { Représenter la lueur } \\
\text { d'espoir }\end{array}$ & $\begin{array}{c}\text { Representar la } \\
\text { esperanza }\end{array}$ \\
\hline To stand for civil rights & EN-3 & $\begin{array}{l}\text { Défendre les droits } \\
\text { civils }\end{array}$ & $\begin{array}{c}\text { Defender los } \\
\text { derechos civiles }\end{array}$ \\
\hline To stand in line & EN-7 & Faire la queue & Hacer cola \\
\hline To support the victims & EN-9 & Soutenir les victimes & $\begin{array}{c}\text { Apoyar a las } \\
\text { víctimas } \\
\end{array}$ \\
\hline To sustain the state & EN-20 & Soutenir l'État & Mantener el estado \\
\hline $\begin{array}{c}\text { To take defensive } \\
\text { measures }\end{array}$ & EN-9 & $\begin{array}{c}\text { Prendre des mesures } \\
\text { défensives }\end{array}$ & $\begin{array}{c}\text { Tomar medidas } \\
\text { defensivas }\end{array}$ \\
\hline To take some steps & EN-19 & $\begin{array}{c}\text { Prendre quelques } \\
\text { mesures }\end{array}$ & Tomar medidas \\
\hline $\begin{array}{c}\text { To take sth by the } \\
\text { heart(s) }\end{array}$ & EN-7 & $\begin{array}{c}\text { Prendre qq'ch au } \\
\text { sérieux }\end{array}$ & $\begin{array}{l}\text { Tomarse algo } \\
\text { seriamente }\end{array}$ \\
\hline $\begin{array}{c}\text { To take tax exemptions } \\
\text { away }\end{array}$ & EN-3 & $\begin{array}{c}\text { Supprimer les } \\
\text { exonérations fiscales }\end{array}$ & $\begin{array}{l}\text { Eliminar las } \\
\text { exenciones de } \\
\text { impuestos }\end{array}$ \\
\hline To take an oath & EN-18 & Prêter serment & Prestar juramento \\
\hline To violate the rights & EN-15 & Violer les droits & Violar los derechos \\
\hline $\begin{array}{c}\text { To wallow in the valley of } \\
\text { despair }\end{array}$ & EN-14 & $\begin{array}{l}\text { Se vautrer dans la } \\
\text { vallée du désespoir }\end{array}$ & $\begin{array}{c}\text { Revolcarse en } \\
\text { el valle de la } \\
\text { desesperación (cit. } \\
\text { lit.) }\end{array}$ \\
\hline To welcome all of you & EN-19 & Vous accueillir tous & $\begin{array}{c}\text { Darles la } \\
\text { bienvenida a todos }\end{array}$ \\
\hline To work for an election & EN-13 & $\begin{array}{c}\text { Travailler pour une } \\
\text { élection }\end{array}$ & $\begin{array}{c}\text { Preparar las } \\
\text { elecciones } \\
\end{array}$ \\
\hline With regard to & EN-16 & $\begin{array}{c}\text { En ce qui } \\
\text { concerne/À l'égard } \\
\text { de }\end{array}$ & $\begin{array}{l}\text { Con respecto a/En } \\
\text { lo referente a }\end{array}$ \\
\hline
\end{tabular}

Figura VIII. Glosario trilingüe (EN, FR, ES) a partir de las UFS en inglés (TO: EN) 


\begin{tabular}{|c|c|c|c|}
\hline $\begin{array}{l}\text { Término en } \\
\text { FRANCÉS } \\
\text { (FR) }\end{array}$ & $\begin{array}{l}\text { Fuente } \\
\text { (TO) }\end{array}$ & $\begin{array}{l}\text { Término en INGLÉS } \\
\text { (EN) }\end{array}$ & $\begin{array}{l}\text { Término en } \\
\text { ESPAÑOL } \\
\text { (ES) }\end{array}$ \\
\hline À juste titre & FR-17 & Quite rightly & Con justa razón \\
\hline À très court terme & FR-3 & $\begin{array}{l}\text { In the very short } \\
\text { term }\end{array}$ & A corto plazo \\
\hline À un rythme soutenable & FR-3 & At a sustainable pace & $\begin{array}{l}\text { A un ritmo } \\
\text { sostenible }\end{array}$ \\
\hline $\begin{array}{l}\text { Aborder une question } \\
\text { fondamentale }\end{array}$ & FR-7 & $\begin{array}{c}\text { To address a } \\
\text { fundamental issue }\end{array}$ & $\begin{array}{c}\text { Abordar una } \\
\text { cuestión importante }\end{array}$ \\
\hline Afficher des taux de ... & FR-7 & $\begin{array}{l}\text { To display the rates } \\
\text { of }\end{array}$ & Mostrar las tasas de \\
\hline $\begin{array}{c}\text { Apprendre au cours de } \\
\text { quelque temps }\end{array}$ & FR-10 & To learn over time & $\begin{array}{l}\text { Ir aprendiendo con } \\
\text { el tiempo }\end{array}$ \\
\hline $\begin{array}{l}\text { Au cours de cette } \\
\text { conférence }\end{array}$ & FR-14 & $\begin{array}{l}\text { During this } \\
\text { conference }\end{array}$ & $\begin{array}{l}\text { Durante esta } \\
\text { conferencia }\end{array}$ \\
\hline $\begin{array}{l}\text { Avec la plus grande } \\
\text { franchisse }\end{array}$ & FR-5 & Frankly & Con total franqueza \\
\hline $\begin{array}{l}\text { Avoir la tentation de } \\
\text { faire qq'ch }\end{array}$ & FR-8 & $\begin{array}{c}\text { To be tempted to } \\
\text { do sth }\end{array}$ & $\begin{array}{c}\text { Tener la tentación de } \\
\text { hacer algo }\end{array}$ \\
\hline $\begin{array}{l}\text { Avoir tous les atouts } \\
\text { pour faire qq'ch }\end{array}$ & FR-18 & $\begin{array}{l}\text { To have all the assets } \\
\text { to get something }\end{array}$ & $\begin{array}{c}\text { Tener ventajas para } \\
\text { lograr algo }\end{array}$ \\
\hline $\begin{array}{l}\text { Baisser la pression } \\
\text { fiscale } \\
\end{array}$ & FR-5 & $\begin{array}{l}\text { To low the tax } \\
\text { burden }\end{array}$ & $\begin{array}{c}\text { Reducir la carga } \\
\text { fiscal }\end{array}$ \\
\hline $\begin{array}{l}\text { Capacité à construire } \\
\text { ensemble un monde } \\
\text { meilleur }\end{array}$ & FR-2 & $\begin{array}{l}\text { To get the ability } \\
\text { of building a better } \\
\text { world together }\end{array}$ & $\begin{array}{c}\text { Ser capaces de crear } \\
\text { un mundo mejor } \\
\text { entre todos }\end{array}$ \\
\hline Ce n'est pas un hasard & FR-9 & It is no accident that & $\begin{array}{l}\text { No es ninguna } \\
\text { casualidad que }\end{array}$ \\
\hline $\begin{array}{l}\text { Compter sur les } \\
\text { compatriotes }\end{array}$ & FR-4 & $\begin{array}{c}\text { To rely on } \\
\text { compatriots }\end{array}$ & $\begin{array}{l}\text { Contar con los } \\
\text { compatriotas }\end{array}$ \\
\hline Constater à regret que & FR-6 & $\begin{array}{l}\text { To notice regretfully } \\
\text { that }\end{array}$ & $\begin{array}{c}\text { Observar con pesar } \\
\text { que }\end{array}$ \\
\hline Consulter le bilan & FR-8 & $\begin{array}{l}\text { To consult the } \\
\text { balance sheet }\end{array}$ & $\begin{array}{c}\text { Consultar el balance } \\
\text { de los resultados }\end{array}$ \\
\hline
\end{tabular}




\begin{tabular}{|c|c|c|c|}
\hline $\begin{array}{l}\text { Contribuer au } \\
\text { rayonnement de la } \\
\text { France }\end{array}$ & FR-6 & $\begin{array}{l}\text { To contribute to } \\
\text { France's influence }\end{array}$ & $\begin{array}{c}\text { Promover la } \\
\text { influencia de Francia }\end{array}$ \\
\hline Depuis lors & FR-2 & Since then & Desde entonces \\
\hline Des mesures concrètes & FR-6 & Concrete measures & Medidas concretas \\
\hline $\begin{array}{l}\text { Dissimuler l'ampleur de } \\
\text { qq'ch }\end{array}$ & FR-2 & $\begin{array}{l}\text { To conceal the } \\
\text { magnitude of sth }\end{array}$ & $\begin{array}{l}\text { Ocultar la magnitud } \\
\text { que tiene algo }\end{array}$ \\
\hline En matière de & FR-3 & In terms of & En materia de \\
\hline En quelque sorte & FR-13 & In other words & Por así decirlo \\
\hline La hausse du chômage & FR-5 & $\begin{array}{c}\text { The rise of } \\
\text { unemployment }\end{array}$ & $\begin{array}{l}\text { El aumento de la } \\
\text { tasa de desempleo }\end{array}$ \\
\hline $\begin{array}{l}\text { Éprouver la moindre } \\
\text { complaisance }\end{array}$ & FR-2 & $\begin{array}{l}\text { To feel the } \\
\text { slightest sense of } \\
\text { complacency }\end{array}$ & $\begin{array}{c}\text { Sentir la más } \\
\text { mínima sensación de } \\
\text { complacencia }\end{array}$ \\
\hline Établir des relations & FR-6 & $\begin{array}{l}\text { To build a } \\
\text { relationship }\end{array}$ & $\begin{array}{l}\text { Establecer una } \\
\text { relación }\end{array}$ \\
\hline $\begin{array}{l}\text { Être à l'appui des efforts } \\
\text { menés }\end{array}$ & FR-2 & $\begin{array}{l}\text { To support the } \\
\text { efforts of }\end{array}$ & Apoyar las medidas \\
\hline Être au cœur de qq'ch & FR-2 & $\begin{array}{l}\text { To be at the heart } \\
\text { of sth }\end{array}$ & $\begin{array}{l}\text { Encontrarse en el } \\
\text { centro de algo }\end{array}$ \\
\hline Être conscient que & FR-2 & To be aware of & $\begin{array}{l}\text { Ser consciente de } \\
\text { algo }\end{array}$ \\
\hline Être d'accord avec & FR-3 & $\begin{array}{l}\text { To agree over } \\
\text { something }\end{array}$ & Estar de acuerdo con \\
\hline Être sur l'estrade & FR-3 & To be on stage & Estar en el ruedo \\
\hline Être un honneur & FR-4 & To be an honour & Ser un honor \\
\hline $\begin{array}{l}\text { Exposer la vision de } \\
\text { qq'ch }\end{array}$ & FR-3 & $\begin{array}{l}\text { To present the vision } \\
\text { of sth }\end{array}$ & $\begin{array}{c}\text { Exponer los } \\
\text { argumentos sobre } \\
\text { algo }\end{array}$ \\
\hline Faires des progrès & FR-7 & To make progress & Progresar \\
\hline Faire reculer & FR-1 & To back up & Retroceder \\
\hline $\begin{array}{c}\text { Faire valoir les lignes } \\
\text { rouges }\end{array}$ & FR-15 & $\begin{array}{l}\text { To bring out the red } \\
\text { lines }\end{array}$ & $\begin{array}{c}\text { Tener en cuenta las } \\
\text { líneas rojas }\end{array}$ \\
\hline $\begin{array}{c}\text { Favoriser la création de } \\
\text { nouveaux emplois }\end{array}$ & FR-5 & $\begin{array}{l}\text { To promote the } \\
\text { creation of new jobs }\end{array}$ & $\begin{array}{c}\text { Promover la creación } \\
\text { de nuevos empleos }\end{array}$ \\
\hline
\end{tabular}




\begin{tabular}{|c|c|c|c|}
\hline $\begin{array}{c}\text { Gérer le budget pour } \\
\text { qq'ch }\end{array}$ & FR-3 & $\begin{array}{c}\text { To manage the } \\
\text { budget }\end{array}$ & $\begin{array}{c}\text { Gestionar } \\
\text { presupuestos }\end{array}$ \\
\hline Il reste tant à faire & FR-8 & $\begin{array}{l}\text { There's so much left } \\
\text { to do }\end{array}$ & $\begin{array}{l}\text { Quedan muchas } \\
\text { cosas por hacer }\end{array}$ \\
\hline Je vous remercie & FR-2 & $\begin{array}{l}\text { Thank you very } \\
\text { much }\end{array}$ & Gracias \\
\hline $\begin{array}{l}\text { La mission que j'ai } \\
\text { confié à }\end{array}$ & FR-6 & $\begin{array}{l}\text { To entrust a mission } \\
\text { to }\end{array}$ & Confiar una misión a \\
\hline $\begin{array}{c}\text { La première urgence, } \\
\text { c'est de... }\end{array}$ & FR-6 & $\begin{array}{l}\text { The first emergency } \\
\text { is }\end{array}$ & $\begin{array}{c}\text { La primera } \\
\text { necesidad que } \\
\text { tenemos es }\end{array}$ \\
\hline $\begin{array}{l}\text { Les règles de la } \\
\text { concurrence }\end{array}$ & FR-5 & $\begin{array}{l}\text { The rules of } \\
\text { competition }\end{array}$ & $\begin{array}{l}\text { Las reglas de la } \\
\text { competencia }\end{array}$ \\
\hline Mettre à mal & FR-4 & To harm & Dañar \\
\hline $\begin{array}{c}\text { Mettre beaucoup } \\
\text { d'énergie à }\end{array}$ & FR-7 & $\begin{array}{l}\text { To put a lot of energy } \\
\text { into }\end{array}$ & Gastar esfuerzos en \\
\hline Mettre en doute & FR-2 & To put sth in doubt & Poner en duda algo \\
\hline Mettre fin au discours & FR-10 & $\begin{array}{l}\text { To get to the end of } \\
\text { the speech }\end{array}$ & Acabar el discurso \\
\hline $\begin{array}{l}\text { Mettre des dollars sur } \\
\text { la table }\end{array}$ & FR-6 & $\begin{array}{c}\text { To lay dollars down } \\
\text { on the table }\end{array}$ & $\begin{array}{c}\text { Poner dinero sobre } \\
\text { la mesa }\end{array}$ \\
\hline Montrer de l'intérêt pou & FR-5 & $\begin{array}{c}\text { To show an interest } \\
\text { in }\end{array}$ & Mostrar interés por \\
\hline Mutations économiques & FR-3 & Economic changes & $\begin{array}{c}\text { Cambios } \\
\text { económicos }\end{array}$ \\
\hline $\begin{array}{l}\text { Nous comptons pour } \\
\text { cela avec l'appui de... }\end{array}$ & FR-10 & $\begin{array}{l}\text { To count on the } \\
\text { support }\end{array}$ & $\begin{array}{c}\text { Contar con el apoyo } \\
\text { de }\end{array}$ \\
\hline $\begin{array}{c}\text { Ouvrir la voie aux } \\
\text { entreprises }\end{array}$ & FR-13 & $\begin{array}{c}\text { To pave the way for } \\
\text { business }\end{array}$ & $\begin{array}{c}\text { Abrir camino para } \\
\text { los negocios }\end{array}$ \\
\hline Partir du principe que... & FR-7 & To assume that & $\begin{array}{l}\text { Partir del principio } \\
\text { de que }\end{array}$ \\
\hline $\begin{array}{c}\text { Porter dans le monde } \\
\text { nos valeurs }\end{array}$ & FR-4 & $\begin{array}{l}\text { To bring our values } \\
\text { to the world }\end{array}$ & $\begin{array}{c}\text { Mostrar al mundo } \\
\text { nuestros valores }\end{array}$ \\
\hline Porter des risques & FR-6 & $\begin{array}{l}\text { To carry/involve } \\
\text { risks/Be risky }\end{array}$ & Correr riesgos \\
\hline Poursuivre l'objectif & FR-2 & To pursue the goal & Perseguir el objetivo \\
\hline
\end{tabular}




\begin{tabular}{|c|c|c|c|}
\hline $\begin{array}{l}\text { Prendre des } \\
\text { responsabilités }\end{array}$ & FR-4 & To take responsibility & $\begin{array}{c}\text { Asumir } \\
\text { responsabilidades }\end{array}$ \\
\hline Prendre l'initiative & FR-5 & To take the initiative & Tomar la iniciativa \\
\hline $\begin{array}{l}\text { Relever les défis en } \\
\text { matière de productivité }\end{array}$ & FR-18 & $\begin{array}{c}\text { To meet productivity } \\
\text { challenges }\end{array}$ & $\begin{array}{c}\text { Responder a los } \\
\text { desafíos de la } \\
\text { productividad }\end{array}$ \\
\hline $\begin{array}{l}\text { Rendre hommage à } \\
\text { qq'ch }\end{array}$ & FR-10 & To pay tribute to & Rendir homenaje a \\
\hline S'inscrire dans la durée & FR-5 & $\begin{array}{c}\text { To be maintained } \\
\text { over time }\end{array}$ & Durar mucho tiempo \\
\hline Sans merci & FR-2 & Mercilessly & Sin piedad \\
\hline $\begin{array}{l}\text { Savoir emprunter } \\
\text { le chemin de la } \\
\text { coopération }\end{array}$ & FR-12 & $\begin{array}{l}\text { To take the path for } \\
\text { cooperation }\end{array}$ & $\begin{array}{l}\text { Iniciar el camino de } \\
\text { la cooperación }\end{array}$ \\
\hline $\begin{array}{l}\text { Se mettre en rapport } \\
\text { avec qq'un }\end{array}$ & FR-1 & $\begin{array}{l}\text { To keep in touch } \\
\text { with somebody }\end{array}$ & $\begin{array}{c}\text { Ponerse en contacto } \\
\text { con alguien }\end{array}$ \\
\hline $\begin{array}{c}\text { Se trouver en territoire } \\
\text { étranger }\end{array}$ & FR-1 & $\begin{array}{c}\text { To be in foreign } \\
\text { territory }\end{array}$ & $\begin{array}{l}\text { Encontrarse en } \\
\text { tierras extrañas }\end{array}$ \\
\hline $\begin{array}{l}\text { Souhaiter au fond de } \\
\text { lui-même }\end{array}$ & FR-16 & $\begin{array}{c}\text { To wish deep down } \\
\text { onelself }\end{array}$ & $\begin{array}{c}\text { Desear algo en el } \\
\text { fondo de uno mismo }\end{array}$ \\
\hline Subsister un risque & FR-16 & To remain a risk & $\begin{array}{l}\text { Quedar/Haber } \\
\text { todavía riesgos }\end{array}$ \\
\hline $\begin{array}{c}\text { Sur la scène } \\
\text { internationale }\end{array}$ & FR-12 & $\begin{array}{l}\text { On the international } \\
\text { scene }\end{array}$ & Internacionalmente \\
\hline Susciter des inquiétudes & FR-3 & To raise concerns & $\begin{array}{c}\text { Aumentar las } \\
\text { preocupaciones } \\
\text { sobre algo }\end{array}$ \\
\hline $\begin{array}{l}\text { Témoigner de la } \\
\text { confiance }\end{array}$ & FR-11 & $\begin{array}{l}\text { To demonstrate } \\
\text { confidence }\end{array}$ & Demostrar confianza \\
\hline $\begin{array}{c}\text { Tenir la mer et } \\
\text { continuer la lutte }\end{array}$ & FR-1 & $\begin{array}{l}\text { To weather the storm } \\
\text { and the battle }\end{array}$ & $\begin{array}{c}\text { Capear el temporal y } \\
\text { la lucha }\end{array}$ \\
\hline Travailler sur des sujets & FR-5 & To work on a topic & $\begin{array}{c}\text { Centrarse en un } \\
\text { tema }\end{array}$ \\
\hline $\begin{array}{l}\text { Traverser un moment } \\
\text { de doutes }\end{array}$ & FR-17 & $\begin{array}{l}\text { To go through a } \\
\text { moment of doubt }\end{array}$ & $\begin{array}{l}\text { Pasar por un } \\
\text { momento de dudas }\end{array}$ \\
\hline
\end{tabular}

Figura IX. Glosario trilingüe (FR, EN, ES) a partir de las UFS en francés (TO: FR) 


\section{Conclusiones y nuevos retos de investigación}

Como hemos podido comprobar, los rasgos generales que caracterizan a las UFS también se han localizado en las UFS propias del lenguaje político, concretamente, en discursos políticos. A tenor de los resultados obtenidos tras el análisis del corpus, observamos que la lengua que hace mayor alarde de UFS (según el corpus de trabajo) sería la lengua inglesa, con un total de hasta 2418 UFS halladas en el corpus en inglés, frente a las 2265 encontradas en el corpus en francés. No obstante, debemos considerar que estos resultados solo pueden aplicarse a la representatividad de este corpus de trabajo, por lo que estos datos son meramente orientativos y no pretenden forjar aquí un patrón definitivo. Evidentemente, estos resultados responden al corpus de trabajo seleccionado, pero deben reconocerse también algunas limitaciones: la longitud de cada discurso (que aunque se ha seleccionado de un modo similar en todos los discursos, no resulta fácil encontrar discursos con exactamente el mismo número de palabras); el contexto (formal o informal); etc. Por su parte, la lengua que ofrece un mayor porcentaje de UFS en lo referido a locuciones sería el francés (29\%), seguido nuevamente del francés para las colocaciones (46\%) y, finalmente, del inglés, con un $33 \%$ de uso de paremias. En lo referente a UFS ontológicas y culturales, ahondando ahora en el terreno semántico, diremos que se ha encontrado, en general, una tendencia al empleo de las UFS ontológicas por encima de las culturales, con una representatividad del $58,4 \%$ en inglés y un $60 \%$ en francés para las primeras, y un 41,6 \% en inglés y un $40 \%$ en francés para las segundas. En general, se ha observado que el uso de las UFS culturales prolifera en el caso de discursos políticos que se han pronunciado en un contexto nacional, donde la función connotativa (Navarro, ibid.) es mucho más clara: la cercanía con el auditorio, el hecho de compartir una misma lengua y cultura y la formalidad que adquiere el evento en el que se pronuncia el discurso pasarían a ser, desde nuestro punto de vista, los factores fundamentales para la utilización de UFS culturales en el discurso político. En el caso de discursos pronunciados en contextos internacionales, aunque también suelen aparecer UFS culturales, el número disminuye drásticamente en comparación con discursos pronunciados en otros ámbitos mucho más familiares para el orador. No obstante, y a la luz de estos resultados, sería conveniente analizar si esta tendencia puede establecerse de 
manera global según el par de lenguas o si, por el contrario, estriba en un uso característico que depende en exclusiva del orador político/a del que se trate.

Llegados a este punto, conviene esgrimir cuáles podrían ser los próximos retos de investigación:

a. Incluir otro tipo de variables a raíz de esta investigación, tales como sexo, edad, país de procedencia, lugar de pronunciamiento del discurso, formalidad del acto en que se pronuncia, etc.

b. Aumentar nuestro análisis de modo que se muestren las variables que se han tenido en cuenta para este estudio, más todas las que nos gustaría añadir: el número de UFS esgrimidas por cada discurso político que ha conformado el corpus, la estimación del porcentaje en relación con UFS ontológicas o culturales por cada discurso, las funciones llevadas a cabo en cada uno (connotativa, icónica, fraseológica), etc.

c. Estudiar todas estas variables de uso de la palabra en el discurso político centrándonos en las UFS, pero concretando la utilización de las mismas en función de cada orador político/a, para conocer las tendencias que marcarían la media y la moda a la hora de establecer resultados definitivos de cara a cada político/a de nuestro corpus.

d. Recopilar la totalidad de UFS, una vez aplicadas todas las variables, para terminar de completar el glosario en línea que se dispondrá en el portal web.

En definitiva, gracias al presente estudio, podemos afirmar que la traducción de UFS en el discurso político se concibe como una tarea de traslación complicada, ya que hay que considerar todos los parámetros culturales que envuelven a dicha UF y conocer cuál es la función que desempeña (ontológica y/o cultural) en el discurso político, para lo cual es indispensable estudiar la UF en su contexto y localizar una expresión equivalente en LM que garantice, además, que se respeta la función retórica y el sentido del mensaje del orador en LO. Para ello, el trabajo documental previo con fichas fraseológicas facilita notablemente esta labor, ya que nos permite acercanos a la UF en cuestión desde un punto de vista tanto lingüístico como cognoscitivo, ahondando en las dificultades de traducción relacionadas con el trasvase cultural del discurso político del que se trate. El glosario ofrecido supone la consumación de todo el proceso descrito. Por su parte, el modelo de análisis fraseológico 
propuesto resulta pertinente para asegurar la calidad en la traslación del mensaje como tarea previa al acto de traducción en sí, y su objetivo es garantizar que se respeta tanto el sentido y función de la UF del TO en el TM como la función discursiva perseguida por el orador en el discurso político en la LO.

Finalmente, confiamos en que la muestra de glosario político en las tres lenguas resultante de nuestra investigación sea un buen recurso documental y traductológico para especialistas, lingüistas y traductores/as.

\section{Referencias bibliográficas}

ARCE CASTILlo, Ángela. (2006) El lenguaje político. Recursos pragmático-discursivos en registros formales e informales. Salamanca: Ratio Legis.

Arellano, Frank, Natalie Vielma y Alexyca Carrero. (2013) "Fraseologías en el discurso político de columnistas de opinión venezolanos." Lengua y habla, 17, pp. 211-218.

BRAzo Millán, Ana Isabel. (2018) "La enseñanza-aprendizaje de expresiones idiomáticas francés-español a través de la traducción." En: García Peinado, Miguel Ángel e Ignacio Ahumada Lara (eds.) 2018. Traducción literaria y discursos traductológicos especializados. Berlín: Peter Lang.

CORPAS PASTOR, Gloria. (1997) Manual de Fraseología Española. Madrid: Gredos.

CORPAS PASTOR, Gloria. (2003) Diez años de investigación en fraseología: estudios sintáctico-semánticos, contrastivos y traductológicos. Madrid: Iberoamericana-Vervuert.

CoseriU, Eugenio. (1987) "Lenguaje y Política." En: Alvar, Manuel (ed.) 1987. El lenguaje político. Madrid: Fundación Friedrich Ebert, Instituto de Cooperación Iberoamericana, pp. 9-31.

FABBRI, Paolo y Marcarino, Aurelia. (2002) "El discurso politico." DeSignis, 2, pp. 17-32.

FERNÁNDEZ LAGUNILLA, Marina. (1999a) La lengua en la comunicación política I: El discurso del poder. Madrid: Arco Libros.

Fuentes RodríGUEZ, Catalina y Esperanza Alcaide Lara. (2002) Mecanismos lingüísticos de la persuasión. Madrid: Arco Libros.

GARCÍA Romero, Marina y Julia Sevilla Muñoz. (2005) "La enseñanza de paremias en contexto y su traducción a través de su presencia en las 'fables' de La Fontaine." Anales de filología francesa, 13, pp. 131-146. 
García Yelo, Marina. (2005) "Consideraciones sobre la didáctica de las expresiones idiomáticas francesas a invidentes." Paremia, 14, pp. 61-70.

García-PAge SÁNCHEZ, Mario. (2008) Introducción a la fraseología española. Barcelona: Anthropos.

GutiÉRREZ DíEZ, Francisco. (1995) "Idiomaticidad y Traducción." Cuadernos de Filología Inglesa, 4, pp. 27-42.

Higueras García, Marta. (2009) "Aprender y enseñar léxico". En: Miquel, Lourdes y Neus Sans (coords.) Didáctica del Español como Lengua Extranjera 3. Madrid: Fundación Actilibre, pp. 111-126.

HurTado AlBiR, Amparo. (2001) Traducción y Traductología. Introducción a la Traductología. Madrid: Cátedra.

LOZANO, Carlos Wenceslao. (1992) "Aproximación al problema de las expresiones idiomáticas y su traducción." Sendebar, 3, pp. 141-156.

LuQue Durán, Juan de Dios y Francisco José Manjón Pozas. (2002) "Claves culturales del diseño de las lenguas. Fundamentos de tipología fraseológica." Estudios de Lingüística del Español, 16 [en línea]. Recuperado de: http://elies. rediris.es/elies16/Claves.html. [Última consulta: 14.09.2019].

Martínez MARÍn, Juan. (1996) Estudios de fraseología española. Málaga: Ágora. Messina FAJARDO, Luisa. (2016) El lenguaje político. Milano: Maggioli Editore.

MogorRón HuerTA, Pedro. (2014) "Las expresiones fijas diatópicas argentinas y mexicanas." En: González Rey, María Isabel. (ed.) Didáctica y Traducción de las Unidades fraseológicas. Santiago: Universidad de Santiago de Compostela, pp. 77-98.

Montoro Del ARCO, Esteban Tomás. (2007) "El porqué de los dichos: la fraseología del vino." Per Abbat: boletín filológico de actualización académica y didáctica, n. ${ }^{\circ}$ 2, pp. 131-136.

NAVARRO, Carmen. (2002) "La fraseología en el discurso político y económico de los medios de comunicación”. En: Cusato, D.A. y L. Frattale (coord.). Atti del XX Convegno dell'AISPI. Messina: Andrea Lippolis, pp. 209-211.

NúÑEZ CABEZAS, Emilio Alejandro y Susana Guerrero Salazar. (2002) El lenguaje político español. Madrid, Cátedra.

Radulescu, Romana Anca. (2006) "Estudio contrastivo de expresiones idiomáticas en español, inglés y rumano." Universidad Complutense [en línea], pp. 111-128. Recuperado de: https://www.uam.es/gruposinv/upstairs/upstairs2/curricula/trabajos/radulescu_2006_estudio.pdf. [Última consulta: 25.09.2019]. 
SERRANO LUCAS, Lucía Clara. (2010) "Metodología para la enseñanza de la fraseología en traducción: la ficha fraseológica como tarea final." Paremia, 19, pp. 197-206.

SEVILla MuÑoz, Julia. (1997) "Fraseología y Traducción." Thelème, 12, pp. 431-440.

Sevilla Muñoz, Julia y Carlos Antonio Crida Álvarez. (2013) "Las paremias y su clasificación". Paremia, 22, pp. 105-114.

TANnen, Deborah. (1999) Cultura de la polémica. Del enfrentamiento al diálogo. Barcelona: Paidós.

TimofeEva, Larissa. (2012) "Sobre la traducción fraseológica." ELUA, 26, pp. 405-432.

VAN DijK, Teun Adrianus. (1996) "Análisis del discurso ideológico." Versión 6, pp. 15-43.

Zuluaga, Alberto. (1997) "Sobre las funciones de los fraseologismos en textos literarios." Paremia 6, pp. 631-640.

ZuluagA, Alberto. (1980) Introducción al estudio de las expresiones fijas. Frankfurt: Peter Lang.

\section{NOTA BIOGRÁFICA / BIONOTA}

MARÍA DEL CARMEN LÓPEZ RUIZ es doctoranda en Traducción e Interpretación por la Universidad de Córdoba (España). Ha obtenido un contrato predoctoral de Formación para el Profesorado Universitario (FPU) otorgado por el Ministerio de Universidades y desarrolla sus labores investigadoras y docentes correspondientes en el seno del Dpto. de Traducción e Interpretación, Filología Francesa, Estudios Semíticos y Documentación de esta misma universidad. Traductora y correctora en la combinación de lenguas EN/FR/ES. Sus líneas de investigación se centran en la Traducción del Discurso Político, Análisis del Discurso y Didáctica de la Traducción. Entre sus publicaciones recientes destacan $\mathrm{La}$ TAV como herramienta de aprendizaje en el estudio del Análisis Crítico del Discurso para la traducción institucional y la comunicación política, en J.J. Gázquez Linares et al., Dykinson, 2020 y Discurso político, pragmática y retórica: un estudio contrastivo desde una perspectiva traductológica de discursos EN/ES de Barack H. Obama y Donald J. Trump, en A. Bueno García, Comares, 2020. 
MARÍA DEL CARMEN LÓPEZ RUIZ is a PhD student in Translation and Interpreting at the University of Córdoba (Spain). She has been awarded a Four-Year PhD Scholarship by the Spanish Ministry of Universities, and develops the related teaching and researching tasks within the Department of Translation and Interpreting, Romance Languages, Semitic Studies and Documentation Science at this university. EN/FR/ES translator and proofreader. Her research interests in Translation Studies encompass different domains: Translation of Political Discourse, Discourse Analysis and Didactics of Translation. Amongst her recent publications are La TAV como herramienta de aprendizaje en el estudio del Análisis Crítico del Discurso para la traducción institucional y la comunicación política, in J.J. Gázquez Linares et al., Dykinson, 2020 and Discurso político, pragmática y retórica: un estudio contrastivo desde una perspectiva traductológica de discursos EN/ES de Barack H. Obama y Donald J. Trump, in A. Bueno García, Comares, 2020.

\section{ANEXO: \\ CORPUS DE TRABAJO}

A. Corpus de discursos en inglés (TO)

\begin{tabular}{|c|c|c|c|}
\hline $\begin{array}{c}\text { N. }^{\mathbf{0}} \\
\text { discurso }\end{array}$ & Fecha & Orador & Fuente TO (EN) \\
\hline 1 & 19.11 .1863 & $\begin{array}{c}\text { Abraham } \\
\text { Lincoln }\end{array}$ & $\begin{array}{c}\text { http://www.abrahamlincolnonline.org/ } \\
\text { lincoln/speeches/gettysburg.htm. [Consulta: } \\
\text { 28.04.19]. }\end{array}$ \\
\hline 2 & 04.06 .09 & $\begin{array}{c}\text { Barack } \\
\text { Obama }\end{array}$ & $\begin{array}{c}\text { https://www.nytimes.com/2009/06/04/us/ } \\
\text { politics/04obama.text.html. [Consulta: } \\
\text { 28.04.19]. }\end{array}$ \\
\hline 3 & 27.07 .16 & Bill Clinton & $\begin{array}{c}\text { https://edition.cnn.com/2016/07/27/politics/ } \\
\text { bill-clinton-speech-transcript/index.html. } \\
\text { [Consulta: 28.04.19]. }\end{array}$ \\
\hline 4 & 14.02 .18 & $\begin{array}{c}\text { Boris } \\
\text { Johnson }\end{array}$ & $\begin{array}{c}\text { https://www.spectator.co.uk/article/full-text- } \\
\text { boris-johnson-s-brexit-speech. [Consulta: } \\
\text { 29.04.19]. }\end{array}$ \\
\hline 5 & 30.01 .18 & $\begin{array}{c}\text { Donald } \\
\text { Trump }\end{array}$ & $\begin{array}{r}\text { https://www.whitehouse.gov/briefings- } \\
\text { statements/president-donald-j-trumps-state- } \\
\text { union-address/. [Consulta: 29.04.19]. }\end{array}$ \\
\hline
\end{tabular}




\begin{tabular}{|c|c|c|c|}
\hline 6 & 08.12 .53 & $\begin{array}{l}\text { Dwight } \\
\text { Eisenhower }\end{array}$ & $\begin{array}{l}\text { https://www.eisenhowerlibrary.gov/sites/ } \\
\text { default/files/research/online-documents/ } \\
\text { atoms-for-peace/atoms-for-peace-draft.pdf. } \\
\text { [Consulta: 30.04.19]. }\end{array}$ \\
\hline 7 & 04.03 .33 & $\begin{array}{l}\text { Franklin D. } \\
\text { Roosevelt }\end{array}$ & $\begin{array}{l}\text { https://avalon.law.yale.edu/20th_century/ } \\
\text { froos1.asp. [Consulta: 30.04.19]. }\end{array}$ \\
\hline 8 & 13.11 .90 & $\begin{array}{l}\text { Geoffrey } \\
\text { Howe }\end{array}$ & $\begin{array}{c}\text { https://www.britpolitics.co.uk/speeches- } \\
\text { sir-geoffrey-howe-resignation/. [Consulta: } \\
\text { 30.04.19]. }\end{array}$ \\
\hline 9 & 21.09 .01 & $\begin{array}{l}\text { George W. } \\
\text { Bush }\end{array}$ & $\begin{array}{l}\text { https://www.theguardian.com/world/2001/ } \\
\text { sep/21/september11.usa13. [Consulta: } \\
\text { 12.05.19]. }\end{array}$ \\
\hline 10 & 04.05 .07 & $\begin{array}{l}\text { Harold } \\
\text { Macmillan }\end{array}$ & $\begin{array}{l}\text { https://www.theguardian.com/ } \\
\text { theguardian/2007/apr/24/greatspeeches. } \\
\text { [Consulta: } 30.04 .19] \text {. }\end{array}$ \\
\hline 11 & 20.01 .1961 & $\begin{array}{l}\text { John F. } \\
\text { Kennedy }\end{array}$ & $\begin{array}{l}\text { https://avalon.law.yale.edu/20th_century/ } \\
\text { kennedy.asp. [Consulta: } 12.05 .19 \text { ]. }\end{array}$ \\
\hline 12 & 03.07 .82 & $\begin{array}{l}\text { Margaret } \\
\text { Thatcher }\end{array}$ & $\begin{array}{c}\text { https://www.margaretthatcher.org/ } \\
\text { document/104989. [Consulta: 13.05.19]. }\end{array}$ \\
\hline 13 & 16.01 .14 & $\begin{array}{l}\text { Mark } \\
\text { Drakeford }\end{array}$ & $\begin{array}{c}\text { http://www.wales.nhs.uk/sitesplus/ } \\
\text { documents/863/Health\%20 } \\
\text { Ministers\%20speech\%20to\%20NHS\%20 } \\
\text { Confederation\%20Annual\%20Conference. } \\
\text { pdf. [Consulta: 30.04.19]. }\end{array}$ \\
\hline 14 & 14.10 .64 & $\begin{array}{l}\text { Martin } \\
\text { Luther King }\end{array}$ & $\begin{array}{l}\text { https://www.nobelprize.org/prizes/ } \\
\text { peace/1964/king/26142-martin-luther-king- } \\
\text { jr-acceptance-speech-1964/ [Consulta: } \\
\text { 10.12.64]. }\end{array}$ \\
\hline 15 & 10.05 .94 & $\begin{array}{l}\text { Nelson } \\
\text { Mandela }\end{array}$ & $\begin{array}{l}\text { https://www.sanews.gov.za/south-africa/ } \\
\text { read-nelson-mandelas-inauguration-speech- } \\
\text { president-sa. [Consulta: 13.05.19]. }\end{array}$ \\
\hline 16 & 23.09 .60 & $\begin{array}{l}\text { Nikita } \\
\text { Khrushchev }\end{array}$ & $\begin{array}{c}\text { https://digitalarchive.wilsoncenter. } \\
\text { org/document/155185. } \\
\text { pdf?v=9f7ac7df82c2cf1162b9f845c67ef067. } \\
\text { [Consulta: } 13.05 .19]\end{array}$ \\
\hline
\end{tabular}




\begin{tabular}{|c|c|c|c|}
\hline 17 & 04.04 .68 & $\begin{array}{c}\text { Robert F. } \\
\text { Kennedy }\end{array}$ & $\begin{array}{c}\text { https://www.jfklibrary.org/learn/about-jfk/ } \\
\text { the-kennedy-family/robert-f-kennedy/ } \\
\text { robert-f-kennedy-speeches/statement- } \\
\text { on-assassination-of-martin-luther-king- } \\
\text { jr-indianapolis-indiana-april-4-1968. } \\
\text { [Consulta: 14.05.19]. }\end{array}$ \\
\hline 18 & 20.01 .81 & $\begin{array}{l}\text { Ronald } \\
\text { Reagan }\end{array}$ & $\begin{array}{c}\text { https://www.reaganfoundation.org/ronald- } \\
\text { reagan/reagan-quotes-speeches/inaugural- } \\
\text { address-1/. [Consulta: 14.05.19]. }\end{array}$ \\
\hline 19 & 13.07 .16 & Theresa May & $\begin{array}{c}\text { https://www.washingtonpost.com/gdpr- } \\
\text { consent/?next_url=https\%3a\%2f\%2fwww. } \\
\text { washingtonpost.com\%2fnews\%2fworldv } \\
\text { iews\%2fwp\%2f2016\%2f07\%2f13\%2ffull- } \\
\text { transcript-may-promises-bold-new-positive- } \\
\text { role-for-britain-after-brexit\%2f. [Consulta: } \\
\text { 15.05.19]. }\end{array}$ \\
\hline 20 & 13.05 .40 & Winston & $\begin{array}{c}\text { Churchill } \\
\text { https://winstonchurchill.org/resources/ } \\
\text { speeches/1940-the-finest-hour/blood-toil- } \\
\text { tears-and-sweat-2/. [Consulta: 15.05.19]. }\end{array}$ \\
\hline
\end{tabular}

B. Corpus de discursos en francés (TO)

\begin{tabular}{|c|c|c|c|}
\hline $\begin{array}{c}\text { N. }^{\circ} \\
\text { discurso }\end{array}$ & Fecha & Orador & Fuente TO (EN) \\
\hline 1 & 18.06 .40 & $\begin{array}{c}\text { Charles de } \\
\text { Gaulle }\end{array}$ & $\begin{array}{r}\text { http://www.charles-de-gaulle.org/ } \\
\text { wp-content/uploads/2017/03/Appel- } \\
\text { \%C3\%A0-la-r\%C3\%A9sistance-sur-les- } \\
\text { ondes-de-la-BBC-Londres.pdf. } \\
\text { [Consulta: 11.05.19]. }\end{array}$ \\
\hline 2 & 18.11 .15 & $\begin{array}{c}\text { Dominique } \\
\text { de Villepin }\end{array}$ & $\begin{array}{c}\text { https://www.lefigaro.fr/politique/ } \\
\text { le-scan/2014/04/08/25001- } \\
\text { 20140408ARTFIG00066-le-discours-de- } \\
\text { villepin-sur-l-irak-a-l-onu.php. [Consulta: } \\
\text { 10.05.19]. }\end{array}$ \\
\hline 3 & 21.11 .2017 & $\begin{array}{c}\text { Édouard } \\
\text { Philippe }\end{array}$ & $\begin{array}{r}\text { https://www.echodescommunes.fr/info_155_ } \\
\text { discours-de-m-edouard-philippe-premier- } \\
\text { ministre-prononce-au-congres-des-maires- } \\
\text { de-france.html. [Consulta: 10.05.19]. }\end{array}$ \\
\hline
\end{tabular}




\begin{tabular}{|c|c|c|c|}
\hline 4 & 14.05 .17 & $\begin{array}{l}\text { Emmanuel } \\
\text { Macron }\end{array}$ & $\begin{array}{c}\text { https://www.elysee.fr/emmanuel- } \\
\text { macron/2017/05/15/discours-d-investiture- } \\
\text { du-president-de-la-republique. [Consulta: } \\
\text { 10.05.19]. }\end{array}$ \\
\hline 5 & 17.11 .09 & $\begin{array}{l}\text { François } \\
\text { Fillon }\end{array}$ & $\begin{array}{l}\text { https://www.vie-publique.fr/ } \\
\text { discours/176986-declaration-de-m-francois- } \\
\text { fillon-premier-ministre-sur-la-politique-de. } \\
\text { [Consulta: } 10.05 .19] \text {. }\end{array}$ \\
\hline 6 & 30.08 .16 & $\begin{array}{l}\text { François } \\
\text { Hollande }\end{array}$ & $\begin{array}{l}\text { https://www.vie-publique.fr/ } \\
\text { discours/200262-declaration-de-m-francois- } \\
\text { hollande-president-de-la-republique-sur-les. } \\
\text { [Consulta: } 10.05 .19] \text {. }\end{array}$ \\
\hline 7 & 30.05 .2000 & $\begin{array}{l}\text { François } \\
\text { Legault }\end{array}$ & $\begin{array}{l}\text { https://www.ccmm.ca/fr/nouvelles/speech-- } \\
\text { guest-speaker-mr-francois-legault-ministre- } \\
\text { detat-a-leducation-et-a-la-jeunesse/. } \\
\text { [Consulta: 11.05.19]. }\end{array}$ \\
\hline 8 & 25.10 .83 & $\begin{array}{l}\text { François } \\
\text { Mitterrand }\end{array}$ & $\begin{array}{l}\text { https://unesdoc.unesco.org/ark:/48223/ } \\
\text { pf0000057371_fre. [Consulta: 11.05.19]. }\end{array}$ \\
\hline 9 & 28.02 .70 & $\begin{array}{l}\text { Georges } \\
\text { Pompidou }\end{array}$ & $\begin{array}{l}\text { https://www.georges-pompidou.org/sites/ } \\
\text { default/files/documents/dossier_avenir_- } \\
\text { discours_longs.pdf. [Consulta: 11.05.19]. }\end{array}$ \\
\hline 10 & 10.10 .18 & $\begin{array}{l}\text { Gautier } \\
\text { Mignot }\end{array}$ & $\begin{array}{l}\text { https://co.ambafrance.org/Fete-nationale- } \\
\text { Discours-de-Monsieur-Gautier-Mignot- } \\
\text { Ambassadeur-de-France-en. [Consulta: } \\
\text { 12.12.19]. }\end{array}$ \\
\hline 11 & 14.03 .97 & $\begin{array}{l}\text { Jacques } \\
\text { Chirac }\end{array}$ & $\begin{array}{l}\text { https://www.vie-publique.fr/ } \\
\text { discours/133796-discours-de-m-jacques- } \\
\text { chirac-president-de-la-republique-sur-les- } \\
\text { relat. [Consulta: 19.05.19]. }\end{array}$ \\
\hline 12 & 05.09 .12 & Jean Charest & $\begin{array}{l}\text { https://www.lesoleil.com/archives/discours- } \\
\text { integral-de-la-demission-de-jean-charest- } \\
\text { 9be7c81803568ee88cd56d4d7b7a8ee7. } \\
\text { [Consulta: 19.05.19]. }\end{array}$ \\
\hline 13 & 28.08 .17 & $\begin{array}{l}\text { Jean-Yves Le } \\
\text { Dirian }\end{array}$ & $\begin{array}{l}\text { https://co.ambafrance.org/Discours-de-Jean- } \\
\text { Yves-Le-Drian-Ouverture-Semaine-des- } \\
\text { ambassadeurs-28-aout-2017. [Consulta: } \\
\text { 19.05.19]. }\end{array}$ \\
\hline 14 & 12.12 .15 & $\begin{array}{l}\text { Laurent } \\
\text { Fabius }\end{array}$ & $\begin{array}{l}\text { https://co.ambafrance.org/Discours-de- } \\
\text { Laurent-Fabius-lors-de-la-cloture-de-la- } \\
\text { COP-21. [Consulta: 19.05.19]. }\end{array}$ \\
\hline
\end{tabular}




\begin{tabular}{|c|c|c|c|}
\hline 15 & 06.09 .35 & Léon Blum & $\begin{array}{l}\text { http://www.lours.org/archives/defaultd53d. } \\
\text { html?pid=508. [Consulta: } 19.05 .19]\end{array}$ \\
\hline 16 & 10.11 .18 & $\begin{array}{l}\text { Marine Le } \\
\quad \text { Pen }\end{array}$ & $\begin{array}{l}\text { https://rassemblementnational.fr/discours/ } \\
\text { intervention-de-marine-le-pen-au- } \\
\text { monument-de-la-victoire/. [Consulta: } \\
\text { 19.05.19]. }\end{array}$ \\
\hline 17 & 27.08 .07 & $\begin{array}{l}\text { Nicolas } \\
\text { Sarkozy }\end{array}$ & $\begin{array}{c}\text { https://es.ambafrance.org/XVeme- } \\
\text { conference-des-ambassadeurs. [Consulta: } \\
\text { 19.05.19]. }\end{array}$ \\
\hline 18 & 21.05 .14 & $\begin{array}{l}\text { Philippe } \\
\text { Couillard }\end{array}$ & $\begin{array}{c}\text { https://webcache.googleusercontent.com/ } \\
\text { search?q=cache:aCVL-cuhwI8J:https://www. } \\
\text { bibliotheque.assnat.qc.ca/ } \\
\text { DepotNumerique_v2/ } \\
\text { AffichageFichier. } \\
\text { aspx\%3Fidf\%3D146878+\&cd= } \\
\text { 8\&hl=es\&ct }=\text { clnk\&gl=uk. [Consulta: } \\
\text { 19.05.19]. }\end{array}$ \\
\hline 19 & 04.01 .19 & Ueli Maurer & $\begin{array}{l}\text { https://www.admin.ch/gov/fr/accueil/ } \\
\text { documentation/discours/allocutions- } \\
\text { nouvel-an/2019.html. [Consulta: 20.05.19]. }\end{array}$ \\
\hline 20 & 27.05 .74 & $\begin{array}{l}\text { Valéry } \\
\text { Giscard } \\
\text { d'Estaing }\end{array}$ & $\begin{array}{l}\text { https://www.elysee.fr/la-presidence/l- } \\
\text { investiture-de-valery-giscard-d-estaing. } \\
\text { [Consulta: 20.05.19]. }\end{array}$ \\
\hline
\end{tabular}

